\title{
LA TORRE DE SANT JOSEP DE VILLAJOYOSA. LA RESTITUCIÓN DEL MONUMENTO ROMANO Y SU CONTEXTO FUNERARIO
}

\author{
THE TOWER OF SANT JOSEP IN VILLAJOYOSA, THE RESTITUTION OF THE ROMAN MONUMENT \\ AND ITS FUNERARY CONTEXT
}

\author{
DIEGO RUIZ-ALCALDE \\ Museo Municipal de Villajoyosa
}

ANA MARÍA CHARQUERO BALLESTER

\section{INTRODUCCIÓN}

La torre de Sant Josep fue construida en el segundo tercio del siglo II d.C., reconvertida en el siglo XVII en torre vigía, utilizada después como almacén y palomar de su casa anexa, posteriormente permaneció semioculta entre las instalaciones de un camping. Fue documentada por numerosos investigadores, entre ellos Gaspar Escolano (Escolano, 1610), Antonio de Valcárcel, Alexandre Laborde en un grabado (1806), Ceán Bermúdez, fue estudiada por L. Abad'y M. Bendala (1985), liberada y excavada desde 2006 y recientemente ha sido reconstruida incluyendo los sillares originales.

Tras la publicación del artículo «Nuevos datos y propuesta de reconstrucción del monumento funerario romano de la Torre de Sant Josep, Villajoyosa, (Alicante)», en el número XXXIII de esta revista (Ruiz-Alcalde y Charquero, 2014), las intervenciones realizadas en 2015 en el entorno del monumento han aportado nuevos datos que se han reflejado en su restitución final. No se pretende incidir en lo ya presentado en el artículo anterior, sino presentar la actualización de las cuestiones modificadas y ampliar otras.

Los trabajos de restauración y restitución, contemplados dentro del proyecto «Trabajos de Acondicionamiento y Consolidación del yacimiento Arqueológico en el entorno del Monumento Funerario Romano de la Torre de Sant Josep de La Vila Joiosa (Alicante)» han sido dirigidos por el arquitecto Santiago Varela, desde el punto de vista arquitectónico, y por uno de los autores de este trabajo (D. Ruiz-Alcalde), desde el punto de vista arqueológico. La reconstrucción y restauración del monumento han sido financiadas por la Generalitat Valenciana y por una mecenas local ${ }^{2}$.

1. Desde aquí queremos agradecer a Lorenzo Abad su ayuda y dedicación desinteresada para la realización de este trabajo.

2. Desde aquí queremos agradecer a Elaine Evans el que haya costeado la reproducción de los tres capiteles que le faltaban al mausoleo a partir del original conservado.
La reconsideración más significativa ha sido la que ha afectado a la reconstrucción de la torre, dado que la localización de ocho nuevos sillares romanos ha llevado a ampliar el número de hiladas del monumento. Asimismo, la localización de prácticamente la totalidad de la planta del recinto funerario que rodea el monumento ha hecho posible conocer el área total que éste ocupaba, ubicar un umbral de acceso al mismo y conocer sus características constructivas, es decir, poder aproximarnos mejor al estudio de este tipo de recintos.

\section{NUEVOS SILLARES HALLADOS EN LA ÚL- TIMA INTERVENCIÓN}

De la torre de Sant Josep ha llegado hasta nuestros días el podium escalonado de cuatro gradas sobre el que se asienta un cuerpo principal liso enmarcado por cuatro pilastras, que a juzgar por los restos conservados en los alrededores estarían coronadas por otros tantos capiteles corintios sobre los que se asentaría el entablamento del monumento. Se engloba dentro del marco de los monumentos turriformes de edícula cerrada, con dos orificios de libaciones situados en los lienzos este y oeste como única conexión con el interior de la torre.

En el pasado artículo presentamos una reconstrucción del monumento basada en un amplio estudio metrológico y tipológico, realizado por nosotros a partir del propuesto en su día por Lorenzo Abad y Manuel Bendala, con el añadido de los 26 sillares localizados hasta ese momento que permitían añadir cinco nuevas hiladas a las seis conservadas. Los proporcionados por esta última intervención han obligado a añadir una nueva hilada al cuerpo del monumento, manteniendo el mismo formato de entablamento ya propuesto. Los 'culpables' de esta modificación han sido dos sillares: uno nuevo hallado en esta última intervención y otro ya conocido, pero que había permanecido parcialmente oculto hasta su reciente extracción. 


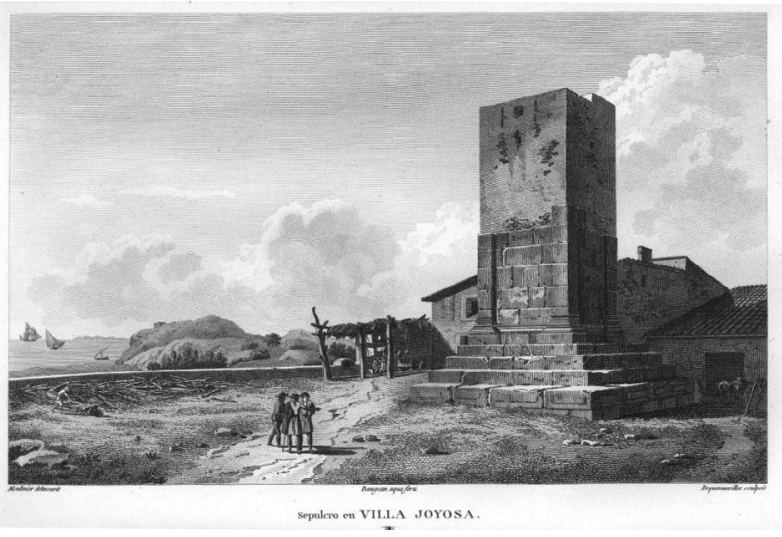

Figura 1: Grabado de Laborde de 1806 (Laborde, 1806).

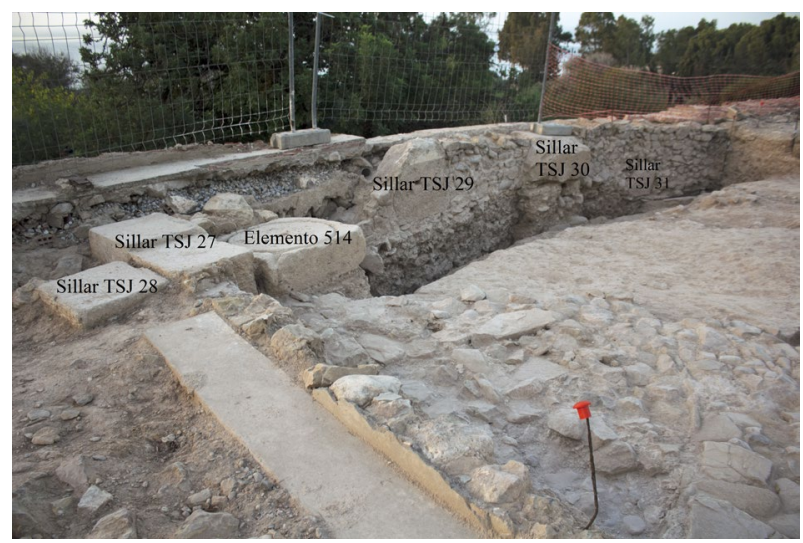

Figura 2: Muro de aterrazamiento fechado entre los siglos XVII y XVIII, con los sillares romanos reutilizados.

Ocho son los sillares localizados en la última campaña de excavación (TSJ 27, 28, 29, 30, 31, 32, 33 y elemento 514); todos ellos han aparecido reutilizados en un muro de aterrazamiento fechado a lo largo los siglos XVII y XVIII y situado en la ladera sur del tossal sobre el que asienta el monumento. Muy posiblemente este muro sea el que ya aparece en el grabado de A. Laborde de 1806 (Figs. 1 y 2).

De estos ocho nuevos sillares, uno corresponde a un pedestal honorífico (TSJ 29); otro es un sillar reutilizado como elemento de prensa en época moderna cuyas medidas difieren de las piezas del mausoleo (E. 514); tres (TSJ 30, 31 y 32) presentan o bien un excesivo estado de erosión de sus caras o bien unas medidas que impiden su reubicación en la torre; y tres de ellos sabemos con absoluta certeza que habrían pertenecido al monumento (TSJ 27, 28, y 33). TSJ 33 y TSJ 27 corresponden a pilastras de esquina y TSJ 28 , al cuerpo principal de la torre.

Los datos decisivos para incluir una hilada más de las planteadas hace unos meses los han aportado el mencionado TSJ 27 y el TSJ 18, un sillar ya localizado en 2012, pero parcialmente oculto por el margen de aterrazamiento de época contemporánea en que se encontraba.

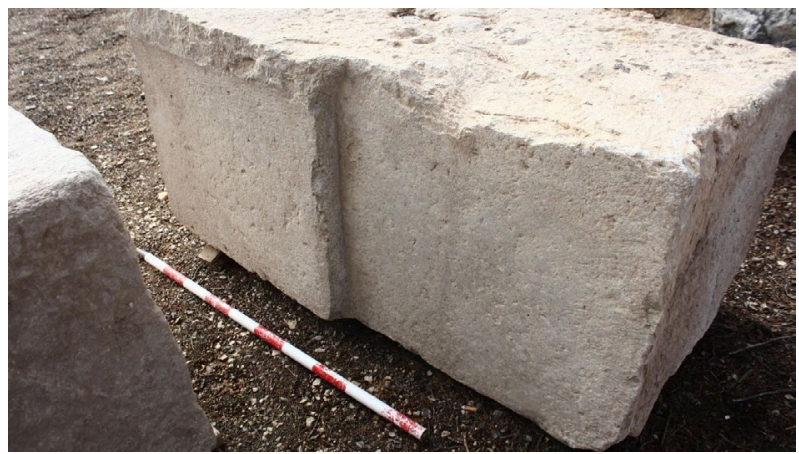

Figura 3: Sillar de esquina de pilastra TSJ 27 con el resalte de arranque de capitel en su esquina superior izquierda.

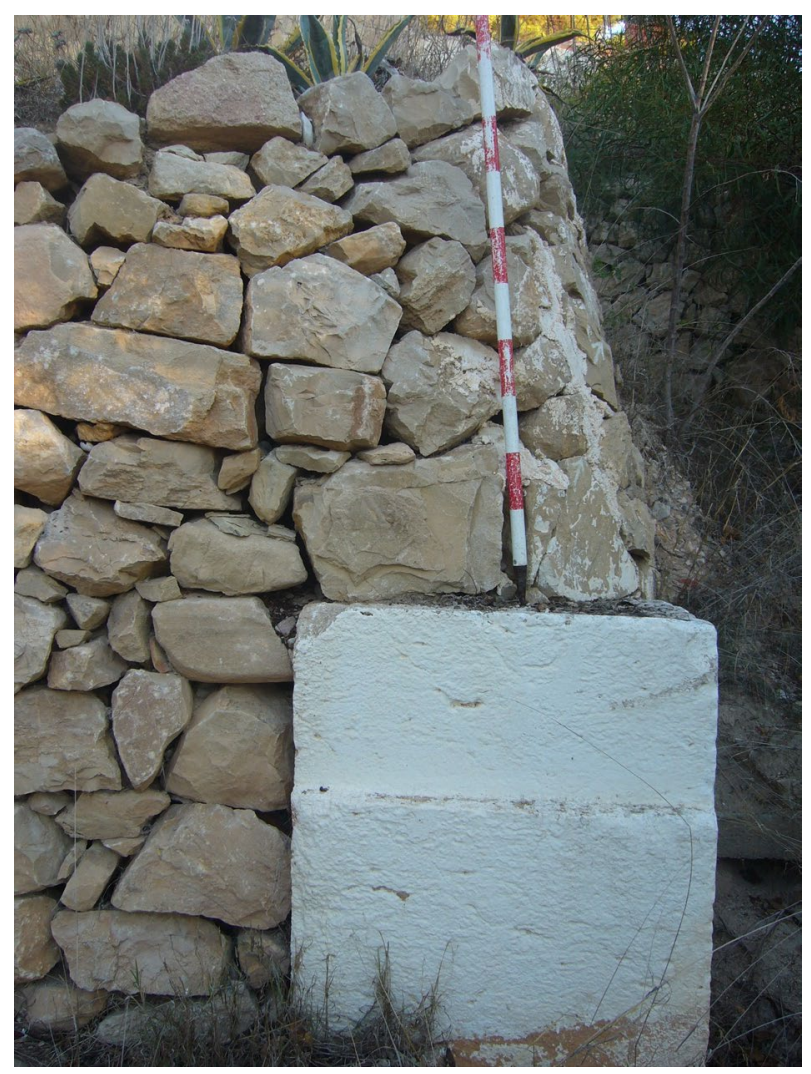

Figura 4: Vista del sillar TSJ 18 incrustado en uno de los márgenes de aterrazamiento de época contemporánea, situado a pocos metros al sur del monumento.

El TSJ 27 presenta en la talla de la pilastra una franja superior con un resalte, ahora roto (Fig. 3). Este resalte se ha interpretado como el arranque de la labra del capitel, es decir, como una zona de tránsito entre el lienzo liso de la torre y el relieve labrado del capitel. Esto no tendría mayores implicaciones de no ser porque la altura de este sillar es de $61 \mathrm{~cm}$, es decir, una altura distinta a las que, como veremos, presentan las hiladas que completan el cuerpo central del monumento, las hiladas sexta y séptima.

El TSJ 18, como hemos dicho, había sido reutilizado en uno de los márgenes de aterrazamiento de época contemporánea situado pocos metros al sur del 


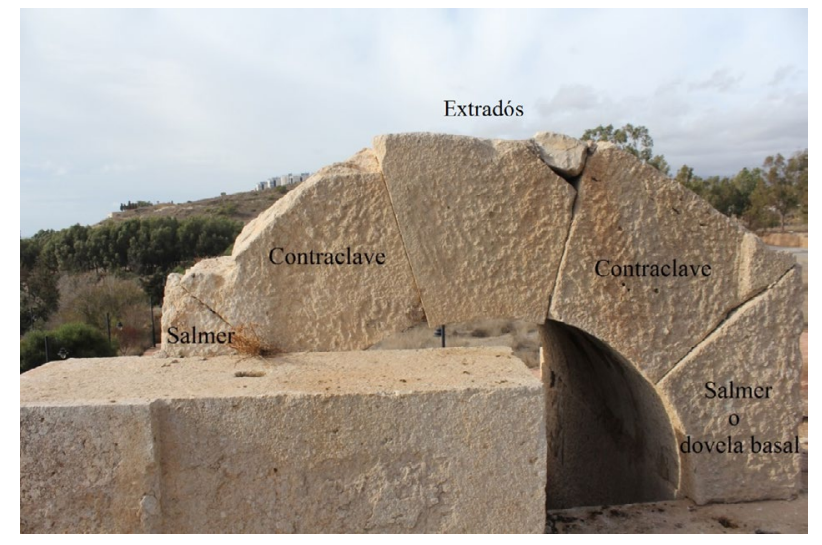

Figura 5: Vista de la bóveda del monumento. Denominación de las partes que la componen.

monumento. Sólo conocíamos su alzado exterior, por una cara, y su lecho por la otra. Ambas caras indicaban que se trataba de un sillar de pilastra (Fig. 4).

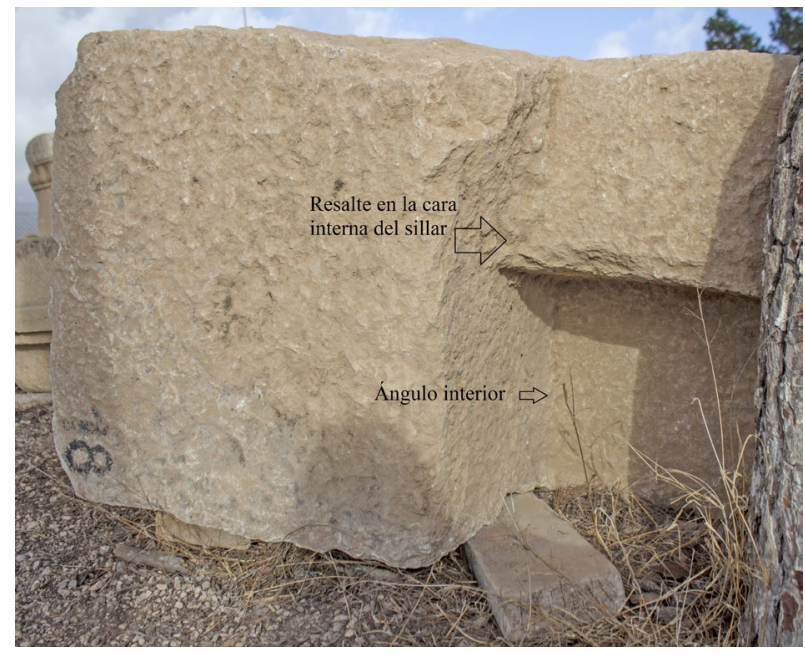

Figura 6: Sillar TSJ 18 exento. Vista de su cara interna.

Como otros sillares esquineros de pilastra, se presuponía que éste, visto en planta, formaba una «L», es
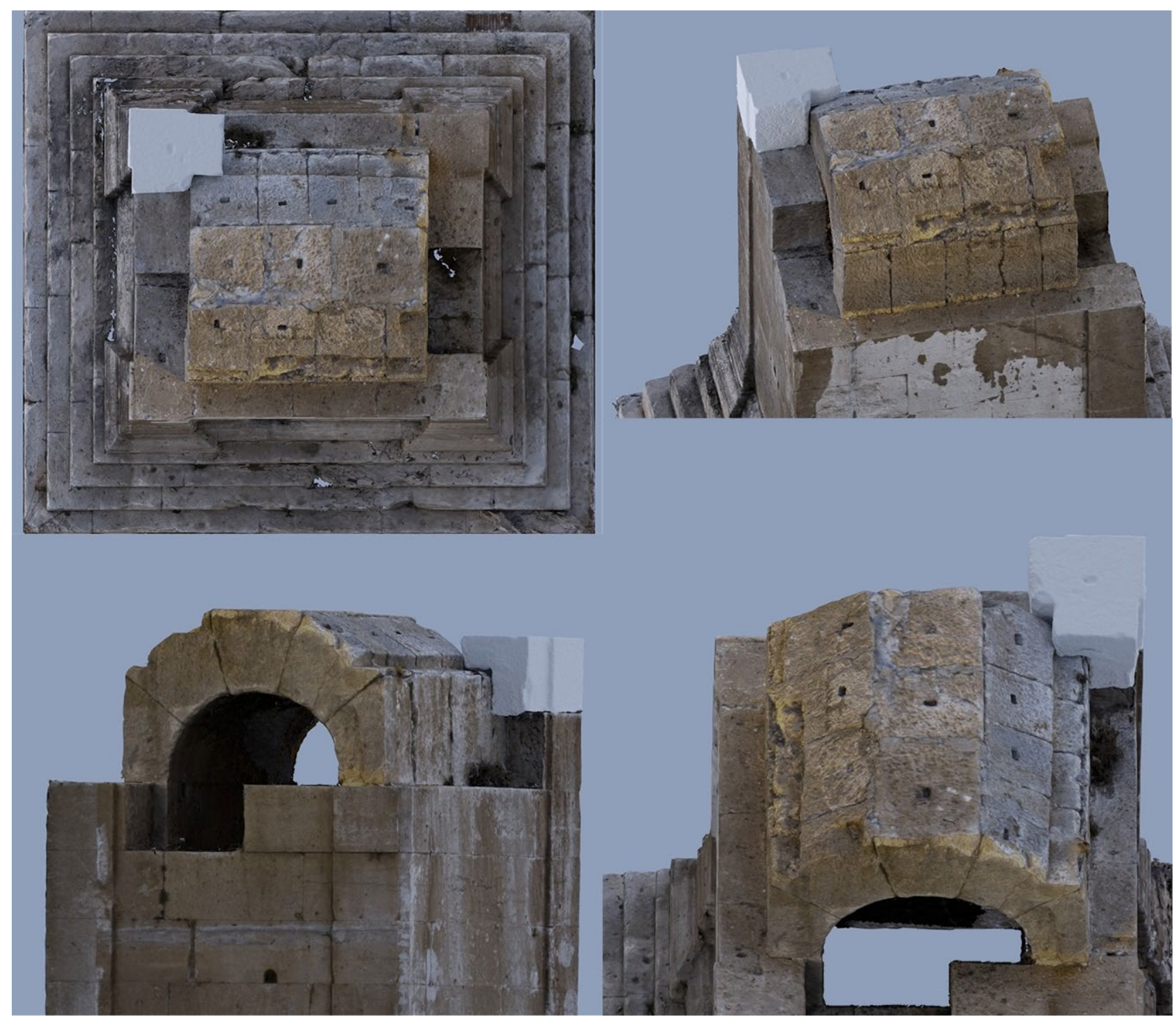

Figura 7: Distintas vistas de la reubicación virtual del sillar TSJ 18. 

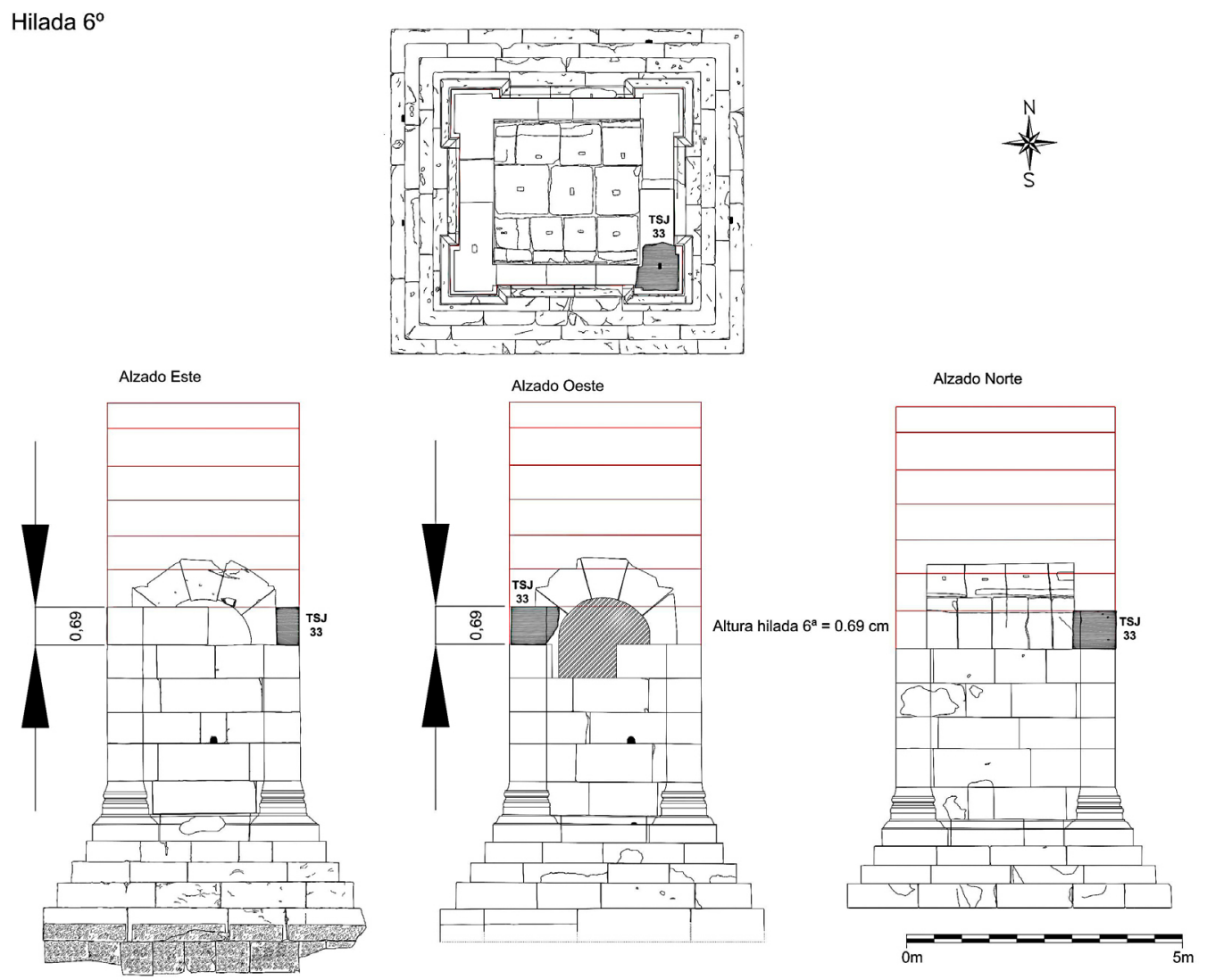

Figura 8: Plano con la reubicación de los sillares en la hilada sexta del monumento.

decir, que tenía un ángulo interior limpio que se acoplaba con el vértice exterior del sillar de arranque de la bóveda (salmer) (Fig. 5). Sin embargo, la liberación y extracción del sillar mostró que su cara interna presentaba un resalte que interrumpía el ángulo recto y conformaba un pequeño espacio interior destinado a acoger el ángulo que forma el salmer con la contraclave (Fig. 6).

Esto ha implicado que este sillar TSJ 18 no fuera ubicado en la sexta hilada, a cuya altura los sillares de arranque de la bóveda presentan un alzado recto, sino que su lugar original estuviera una hilada más arriba, en la séptima, altura a la que arranca el extradós de la bóveda, al que el TSJ 18 se acopla exteriormente (Fig. 7). Ésta es la única pieza original conservada actualmente de la séptima hilada del monumento, lo que establece la altura de la hilada en $68 \mathrm{~cm}$.

Estos datos de la hilada séptima, unidos al hallazgo del sillar TSJ 27, modifican el número de hiladas faltantes del monumento, ya que el TSJ 27 presenta en su cara vista el resalte de arranque de capitel mencionado, lo que obliga a ubicarlo en la hilada inmediatamente inferior a la línea de capiteles. Por otra parte, este sillar de arranque de capitel TSJ 27 presenta, como hemos dicho, una altura de $61 \mathrm{~cm}$, lo que significa que no podría pertenecer ni a la hilada sexta ni a la séptima, ya que la altura de la sexta viene marcada por el único sillar de la misma que aún conserva el monumento $-69 \mathrm{~cm}-\mathrm{y}$ la altura de la séptima la marca el recién descrito TSJ 18 con una altura de $68 \mathrm{~cm}$. No cabe duda, por tanto, de que el sillar de arranque de capitel TSJ 27 pertenece a la octava hilada del monumento, justo antes de la hilada de capiteles que da paso al entablamento, obligando por tanto a añadir una hilada más a la anterior propuesta.

\section{LA RESTITUCIÓN DEL MONUMENTO}

De este modo, estos nuevos datos aquí reflejados nos permiten afirmar que la torre presentaba en origen un total de 12 hiladas hasta la línea de cornisa, es decir, las seis hiladas del cuerpo actualmente conservadas (de las que la última o sexta hilada sólo conserva un sillar in situ en el monumento), más seis hiladas faltantes;

- dos hiladas más de lienzo liso (hiladas séptima y octava), siendo la hilada octava la nueva hilada incluida en la anastilosis.

- una hilada donde estarían ubicados los capiteles

- tres hiladas de entablamento, la de arquitrabe, la de friso y la de cornisa.

A la luz de estos nuevos datos, la anastilosis definitiva se ha ejecutado de acuerdo al siguiente planteamiento:

-Hilada sexta, de la que se ha conservado in situ únicamente un sillar en la esquina sureste de la torre y que 
Hilada $7^{\circ}$
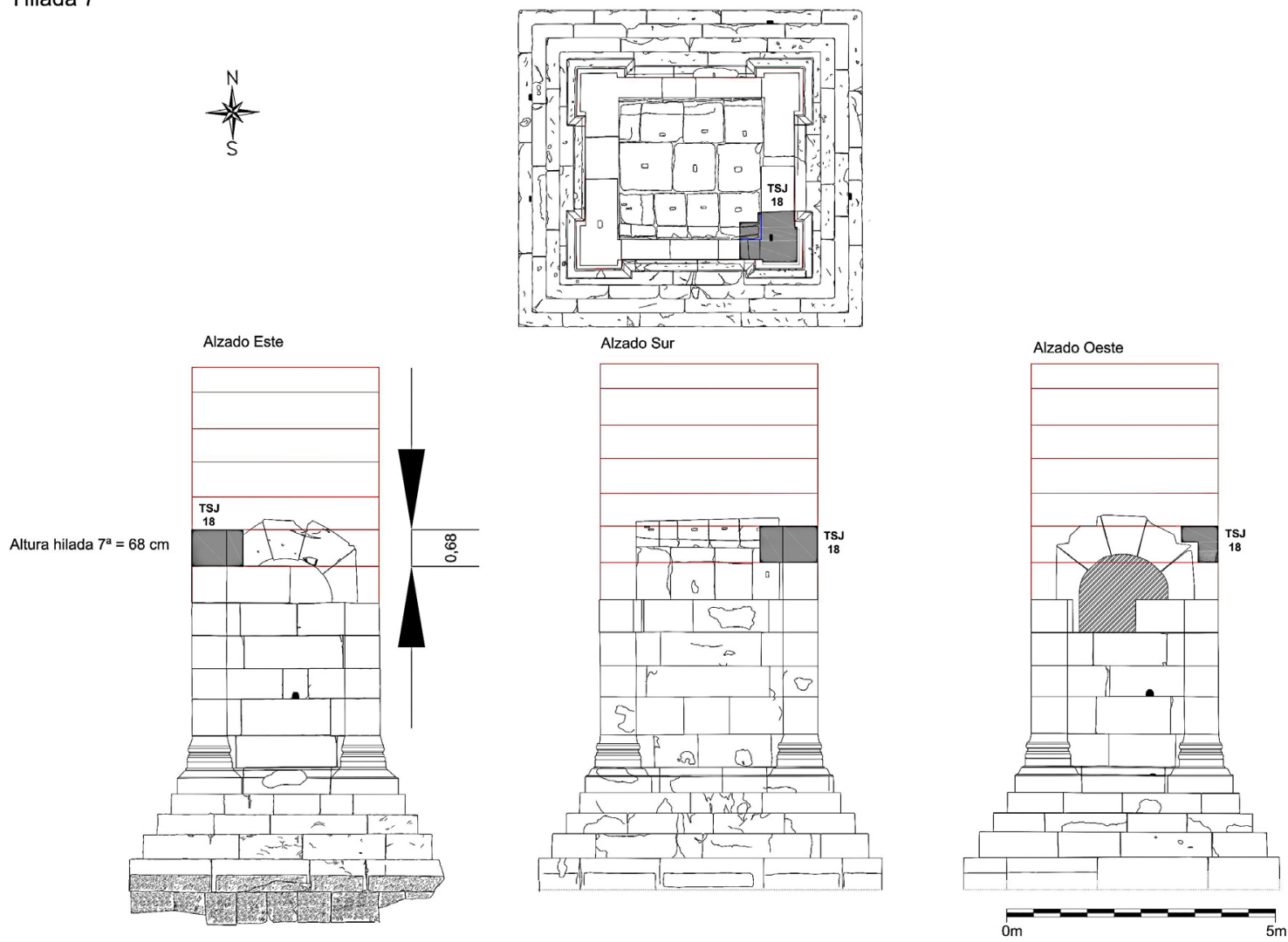

Figura 9: Plano con la reubicación de los sillares en la hilada séptima del monumento.

presenta una altura de $69 \mathrm{~cm}$. Durante la campaña de 2014 se localizó y estudió el TSJ 33, un sillar de pilastra con esa misma altura, cuya ubicación original en el monumento habría sido la esquina noroeste, donde ha sido reubicado (Fig. 8).

-Hilada séptima, a la que pertenece el sillar TSJ 18, una pieza de esquina de pilastra y que marca una altura de $68 \mathrm{~cm}$ para esta hilada. Como hemos visto, su única ubicación posible es la esquina sureste del monumento (Figs. 9, 10, 11 y 12).

-Hilada octava, la «hilada de capiteles» en la anterior propuesta, se convierte ahora en la hilada inmediatamente inferior a la de los capiteles con la inclusión en la misma del sillar TSJ 27, que presenta el resalte con el arranque de la labra del capitel (Fig. 13). Además, otro de los sillares localizados en esta campaña -el TSJ 28- presenta también $61 \mathrm{~cm}$ de altura, es decir, que también habría pertenecido a esta octava hilada. Al recolocar estos dos sillares en el monumento, que se dispusieron de forma contigua en la misma hilada (Fig. 14), quedó comprobado, como ya se intuía en la planimetría realizada, que las aristas de ambos se adaptaban perfectamente la una a la otra siguiendo la forma natural de la piedra y no como consecuencia de un corte artificial del cantero. Sin embargo, cada uno de estos sillares presenta una cavidad rectangular

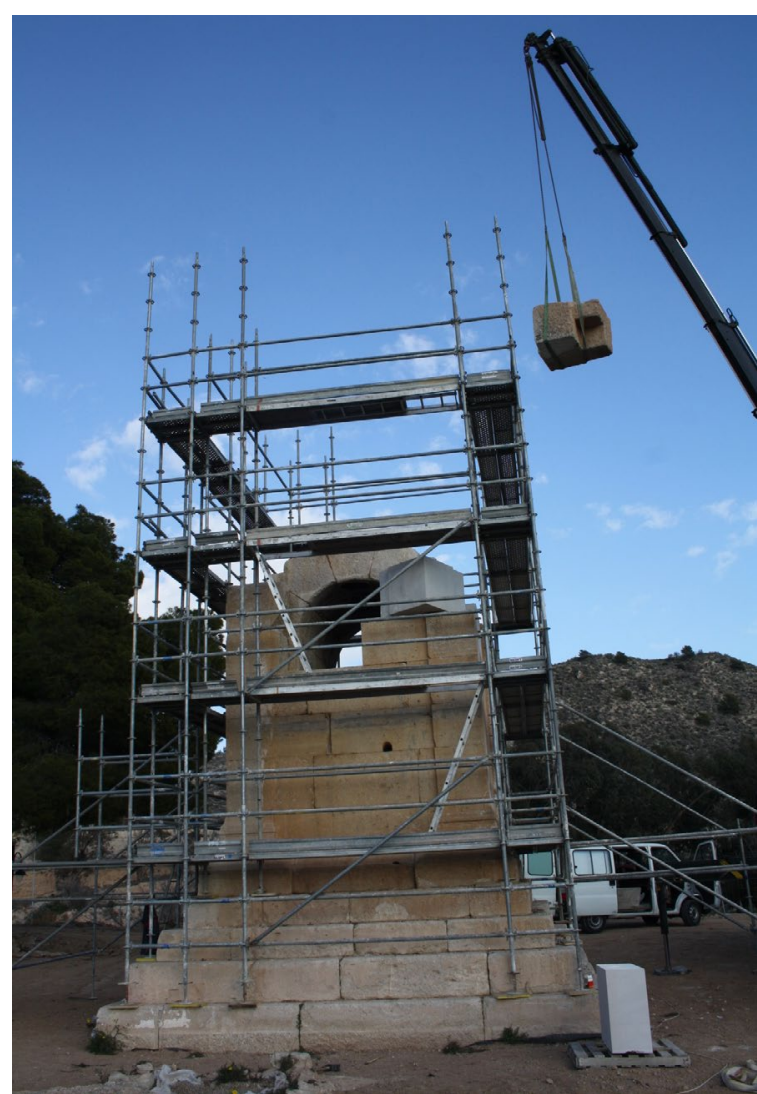

Figura 10: Proceso de reubicación del sillar TSJ 18. 


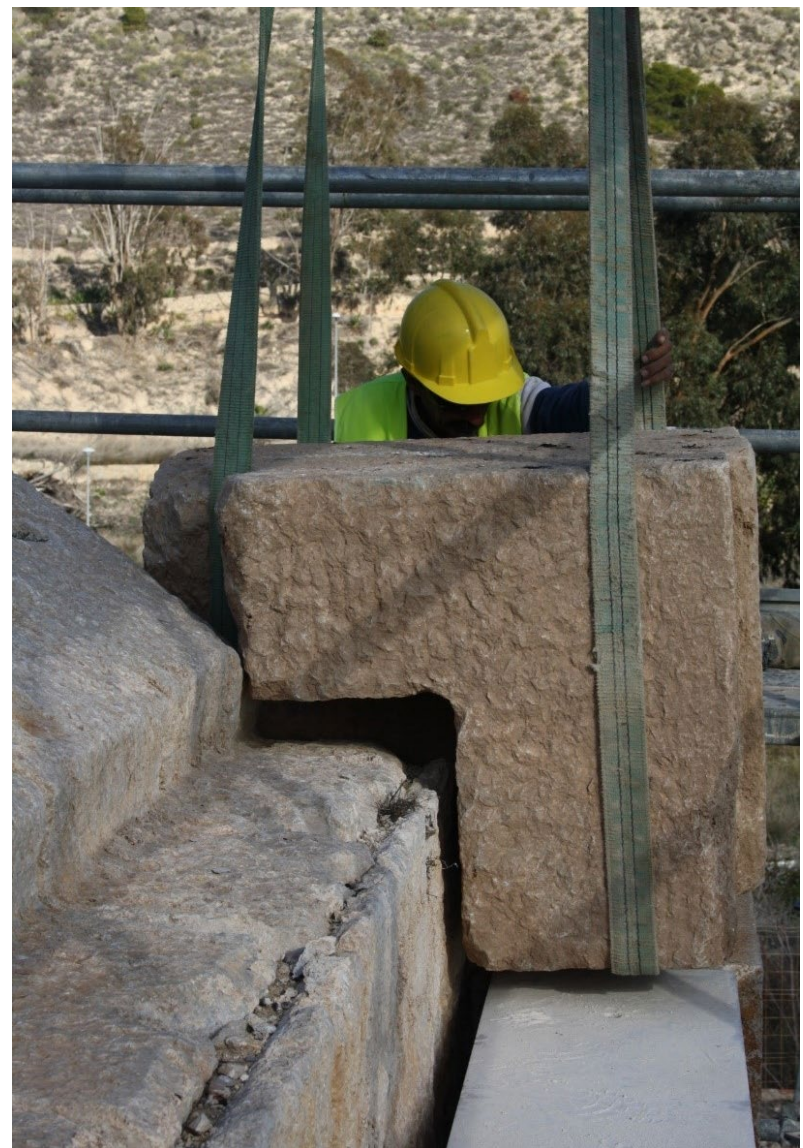

Figura 11: Momento de reubicación y ajuste del sillar TSJ 18. Vista desde el oeste.

independiente y centrada en el lecho del bloque, lo que nos lleva a pensar que ambos sillares eran en origen uno solo que debió fracturarse durante el traslado desde la cantera, y una vez a pie del monumento, aprovechando esta eventualidad ${ }^{3}$, se labraron sendas mortajas para su desplazamiento y colocación, seguramente contigua.

El resto de hiladas no ha sufrido modificación alguna a raíz de los nuevos datos obtenidos. Su situación se mantiene como en la propuesta anterior, incluyendo un total de 9 sillares originales, y es la siguiente (Fig. 15):

-Hilada novena o hilada de capiteles. En este caso, el capitel original conservado marca una altura de 65 $\mathrm{cm}$, y sus características morfológicas permiten ubicarlo en cualquiera de las 4 esquinas del monumento. Finalmente se optó por su colocación en la esquina noroeste, flanco más visible desde el acceso a la parcela de la torre (Fig. 16).

3. La cara vista del sillar TSJ 28 presenta una superficie algo suavizada y desgastada, fruto de su reutilización en época moderna como parte de un vano, es decir, resultado del tránsito a pie por encima del mismo.

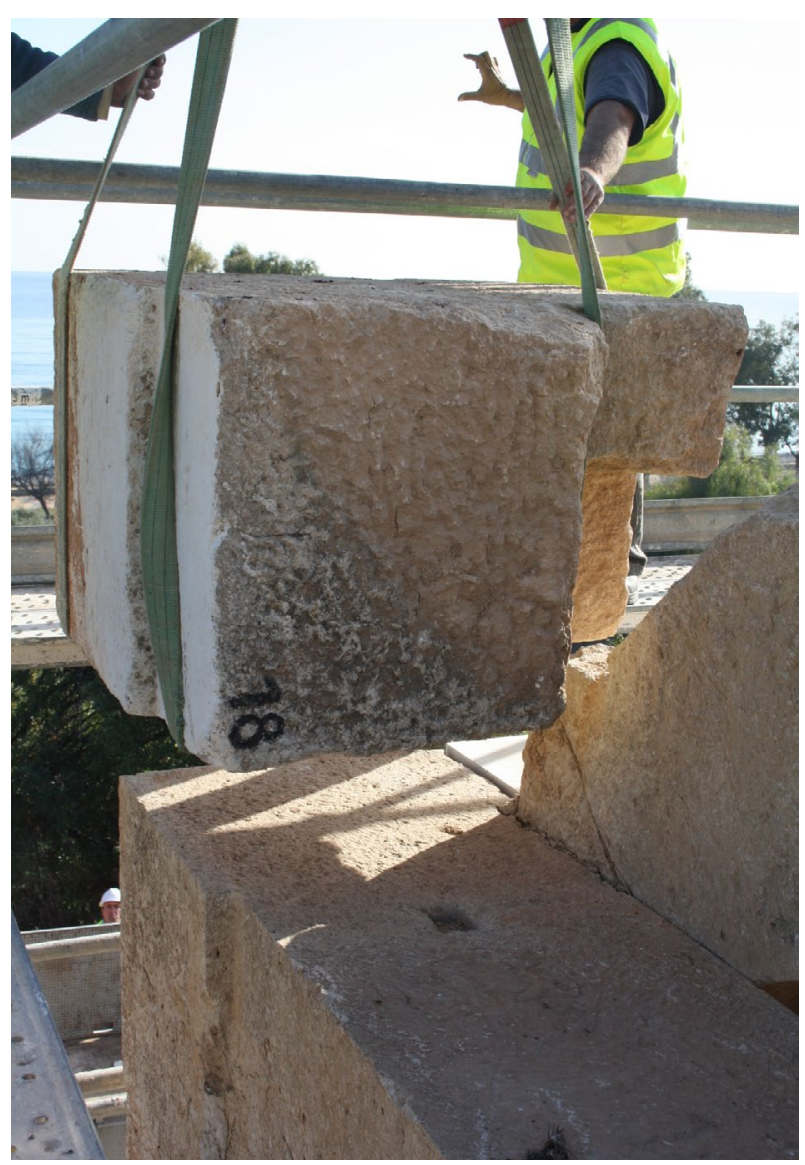

Figura 12: Reubicación y ajuste del sillar TSJ 18.Vista desde el norte.

Dada la inexistencia de más capiteles originales, para la coronación de las otras tres esquinas de pilastras se tallaron tres capiteles más de las mismas características que el original ${ }^{4}$ (Fig. 17).

-Hilada décima o de arquitrabe. De esta hilada se conservaba un solo elemento que se ha colocado en la cara norte del mausoleo. Este sillar ha marcado la altura de la hilada en $62 \mathrm{~cm}$. Dado que se trata de un sillar moldurado con voladizo de $8 \mathrm{~cm}$, se ha colocado su arista exterior inferior a la altura de la línea de pilastras, es decir, $4,5 \mathrm{~cm}$ sobresalientes respecto a la línea del lienzo del cuerpo liso de la torre, en base a paralelos con otros monumentos de este tipo (Fig. 18).

-Hilada undécima o de friso. Únicamente se ha conservado un elemento que pensamos pertenece al friso del monumento. Es el TSJ 6, un sillar liso de $68 \mathrm{~cm}$ de altura y que, por tanto, marca la altura de la hilada del friso. La línea exterior de este sillar se ha colocado tomando como referencia la línea de fachada del monumento, tal y como aparece en otros monumentos con este tipo de entablamento corintio. Para la ubicación

4. Los trabajos de cantería fueron realizados por Miquel Carles Mantero, cantero especializado. 
Hilada $8^{\circ}$ (arranque de capitel)
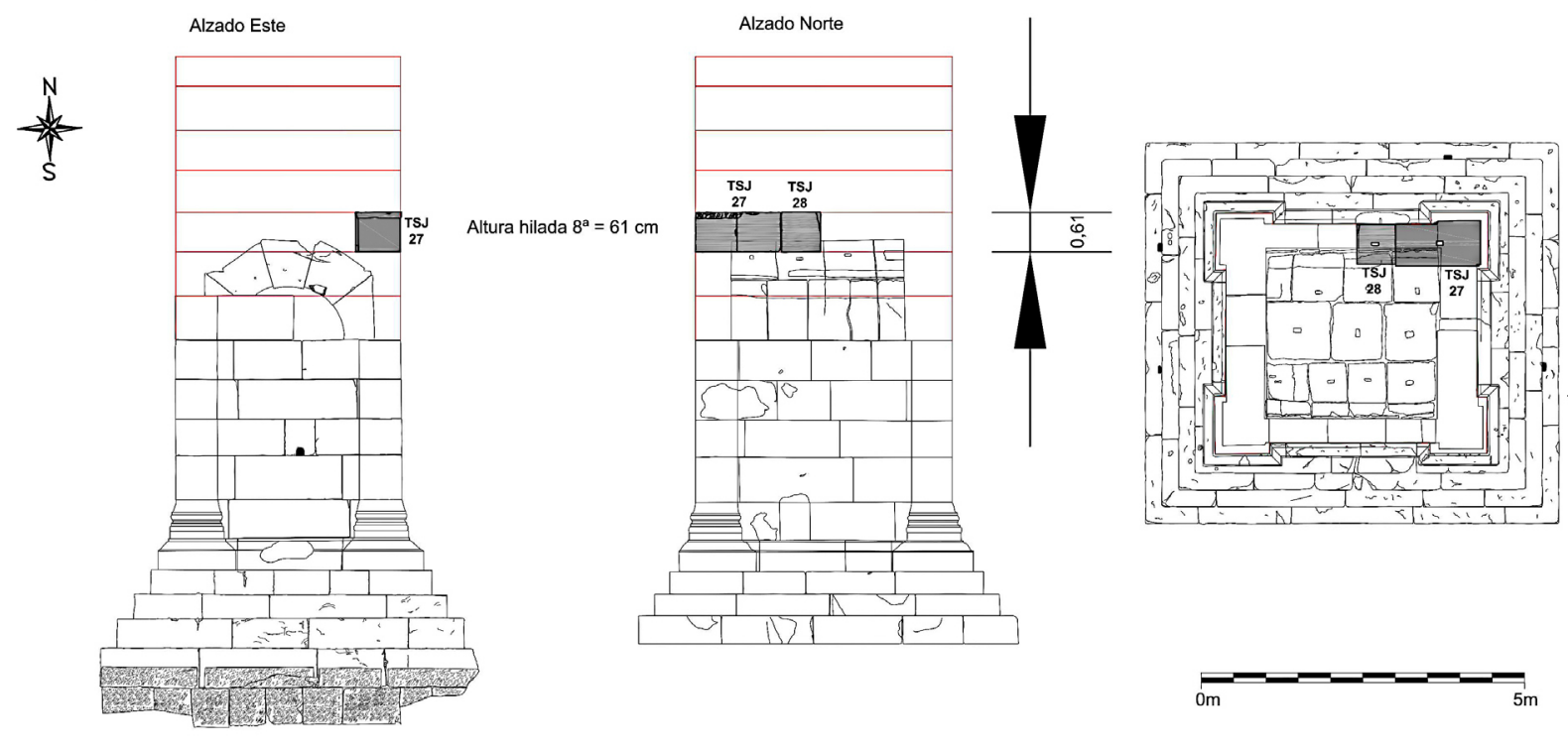

Figura 13: Plano de reubicación de los sillares en la hilada octava del monumento.

de esta única pieza de friso original se ha optado por la fachada sur del monumento (Fig. 19).

-Hilada duodécima o de cornisa. De esta última hilada han llegado a la actualidad cuatro sillares originales (TSJ 11, 17, 22 y 24), de los que sólo dos se han reubicado en el monumento (TSJ 17 y 22) (Fig. 20). Al tratarse de sillares de cornisa moldurados, presentan un voladizo de $37 \mathrm{~cm}$, por lo que el estado de conservación de su base ha sido determinante para decidir su inclusión o no en la restitución. En el caso de los TSJ 11 y 24, esta base estaba tan incompleta que no era aconsejable su reubicación sin alterar el sillar original para fijarlo. Descartada esta opción, son los sillares TSJ 17 en la cara norte y TSJ 22 en la cara sur, las piezas originales que forman parte de la cornisa reconstruida.

Para hacernos una idea de lo que ha supuesto el recrecido de estas hiladas, podemos traer a colación algunas medidas. Antes de la reconstrucción, la altura del monumento desde la base de la grada inferior hasta la última hilada en pie era de $6,05 \mathrm{~m}$; la reconstrucción de las hiladas faltantes le ha añadido una altura de 3,1 $\mathrm{m}$, es decir, que ahora toda la torre reconstruida mide 9,71 m (Fig. 21).

Vale la pena, además, revisar cómo ha afectado a la metrología del monumento la inclusión de una nueva hilada. Recordemos que L. Abad y M. Bendala identificaron en él una serie de medidas traducibles en pies romanos $(1 \mathrm{pie}=0,296 \mathrm{~m})$, y tomaron como base la relación 2:1 para el monumento, es decir, calcularon que la altura total de la torre sería el doble de la anchura máxima del graderío; el monumento original habría tenido 43,5 pies romanos, incluyendo el pyramidium (Fig. 22). Una de las aportaciones centrales del pasado artículo fue la inclusión, en esa metrología planteada,

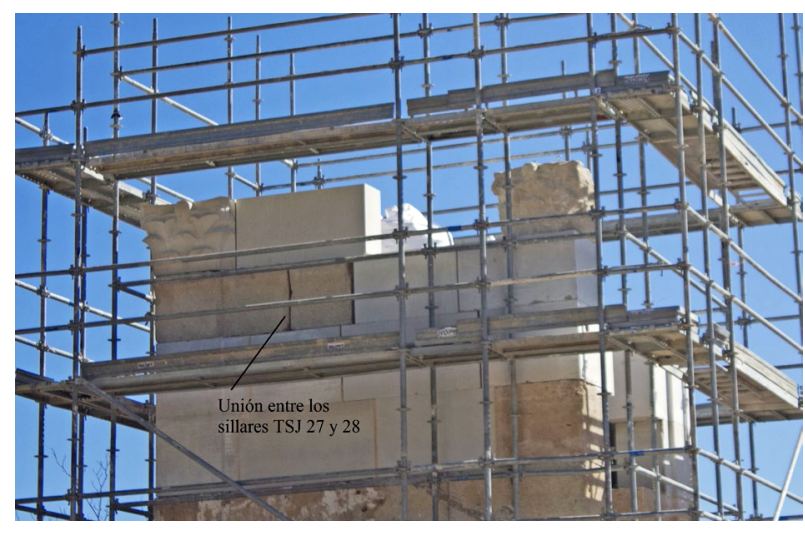

Figura 14: Vista de los sillares TSJ 27 y 28 tras su reubicación.

de las medidas reales que presentaban los sillares conservados. Estas medidas reales apenas modificaron el planteamiento teórico en medio pie. Y se mantuvo, con esta pequeña diferencia, el desglose de medidas inicialmente propuesto por L. Abad y M. Bendala, que era el siguiente; sobre un pódium de 7 pies, se alzaría un cuerpo, incluyendo los capiteles, de 17 pies, sobre el que apoyaría un entablamento de 6 pies, coronado por un pyramidium de 13 pies. Ahora bien, la inclusión de una nueva hilada en este planteamiento, unida a pequeñas variaciones en la altura de alguna de las hiladas, ha determinado que el cuerpo, incluidos los capiteles, alcance una altura de 20 pies; el entablamento mantiene la misma altura, pero el pyramidium se ve reducido a 10 pies para que la altura total del monumento siga sumando 43 pies, es decir, el doble que la anchura máxima del graderío, 21,5 pies.

A falta de haber localizado restos que pudieran pertenecer al pyramidium, los paralelos apuntan la existencia de éste en este tipo de monumentos. Pyramidia de características similares al nuestro y de los que se 


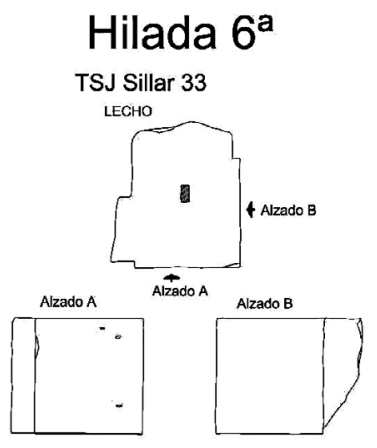

Hilada $8^{a}$

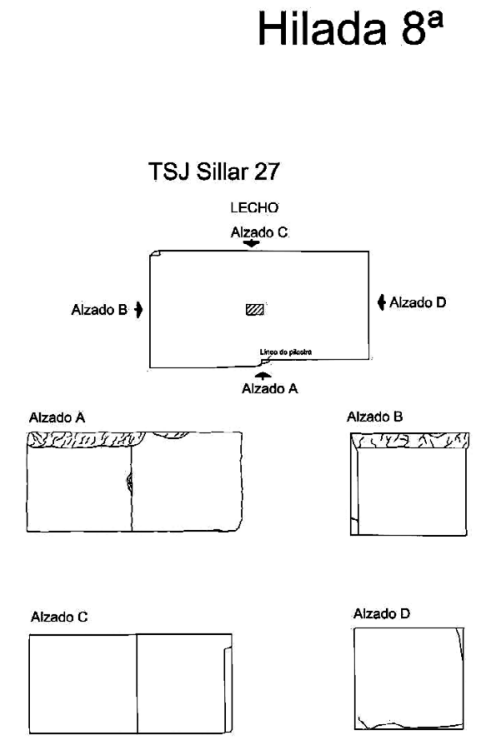

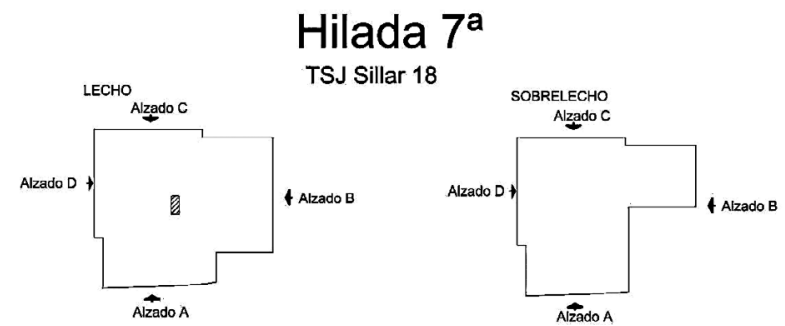
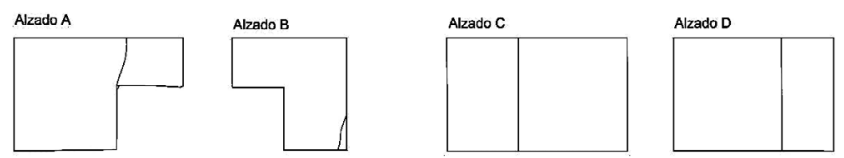

Hilada $9^{a}$

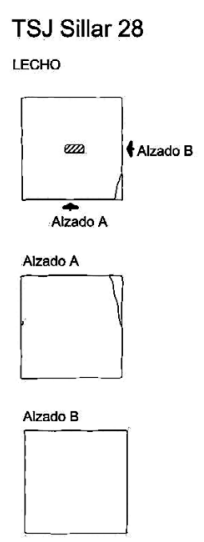

TSJ Sillar 28
Hilada $10^{\mathrm{a}}$

Arquitrabe

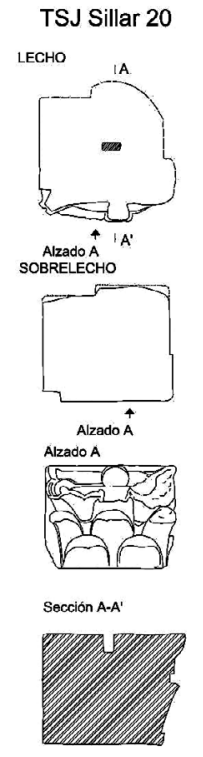

Hilada $12^{\mathrm{a}}$

Cornisa
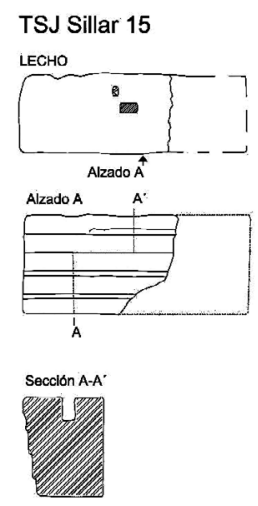

\section{Hilada $11^{\mathrm{a}}$ \\ Friso}

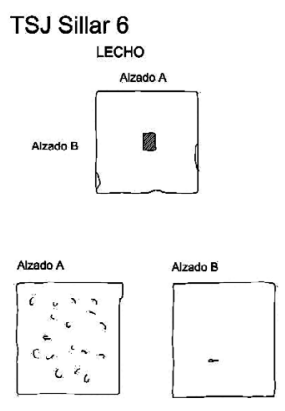

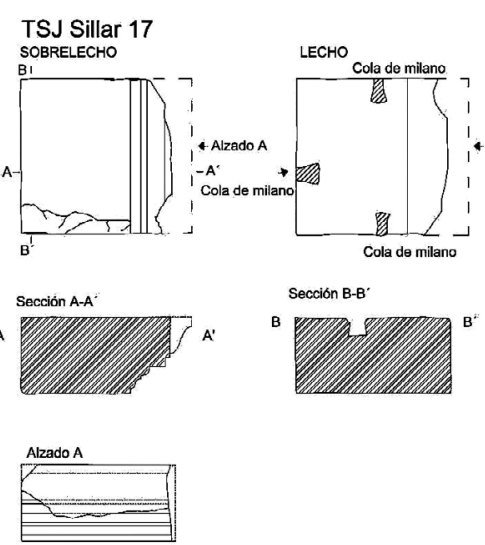

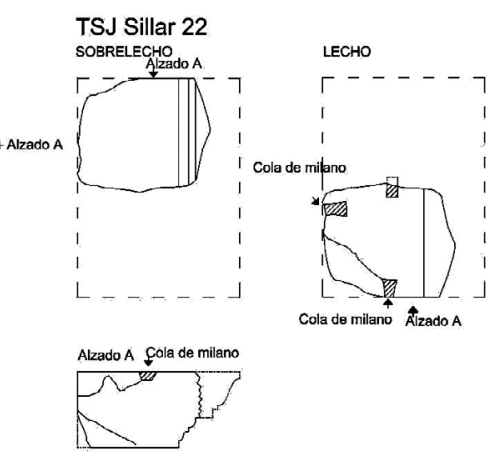

om

Figura 15: Dibujos de los sillares finalmente reubicados en el monumento. 


\section{Hilada $9^{a}$ (línea de capiteles)}
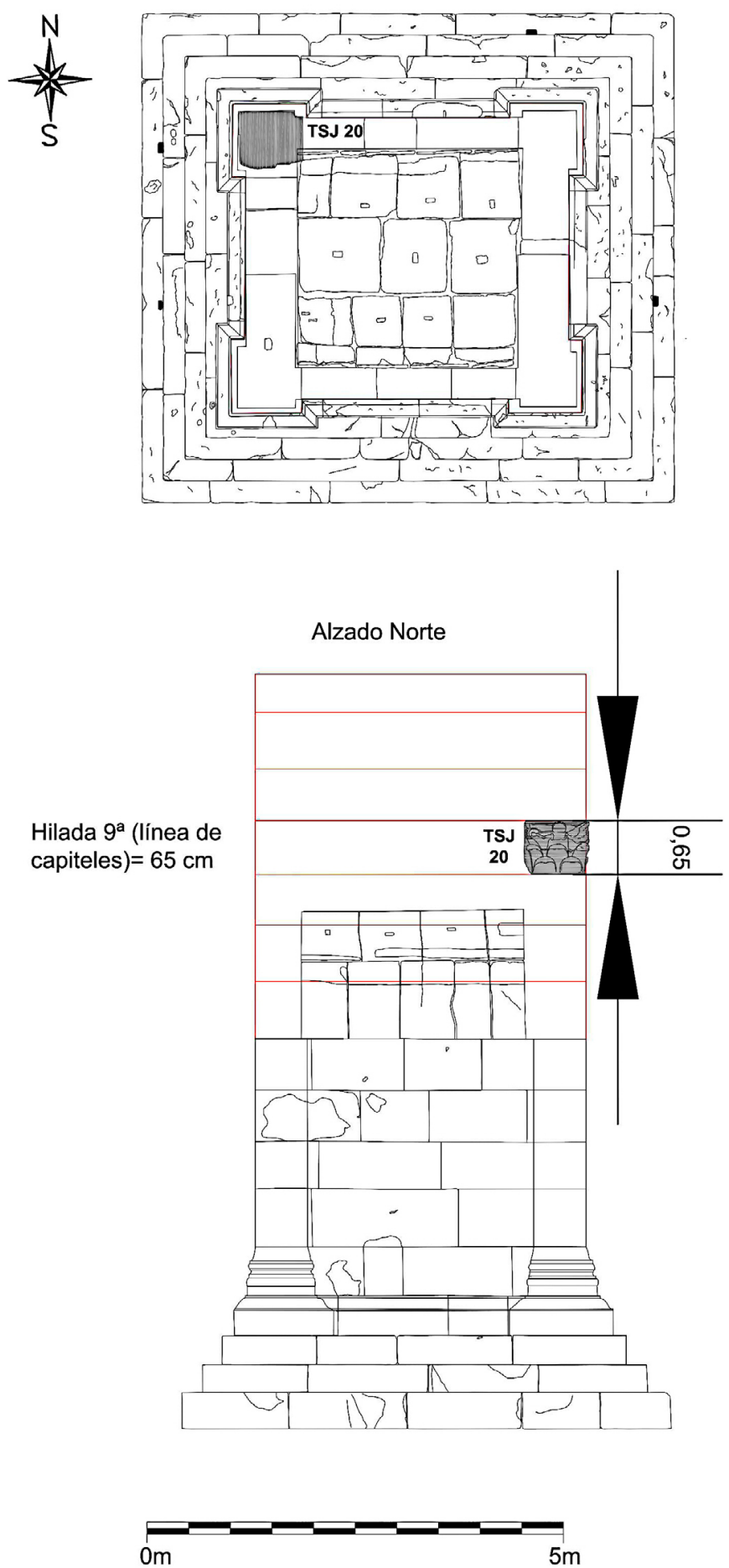

Figura 16: Plano de reubicación de los sillares en la hilada novena del monumento.

conserven algún resto en la actualidad, los encontramos en monumentos norteafricanos como los de Akbou o de Maktar (Romanelli, 1970; Prados Martínez, 2008, 287, fig. 317) o en monumentos orientales como el de Kamouh el Hermel en el Líbano. Dentro de los monumentos hispanos conservan su pyramidium el de El Hornillo de Santa Catalina de Baelo Claudia o el monumento de Alcalá la Real en Jaén que conserva la cubierta piramidal de ocho escalones en el exterior (Ruiz Osuna, 2008, 291). Las dimensiones de estos pyramidia no parecen guardar una relación proporcional con los monumentos a los que coronan; el 


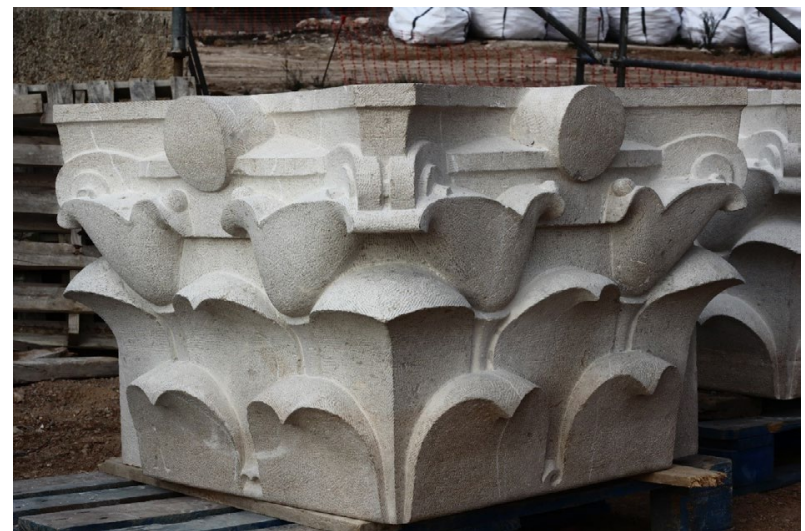

Figura 17: Una de las tres reproducciones de los capiteles tallados a mano.

pyramidium de Al-Bara en Siria es el doble de alto que el cuerpo al que remata, el de Piton-du-Akbou aunque hoy incompleto, alcanzaría una altura similar a la del cuerpo de su monumento, y el de Kamouh el Hermel, tiene una altura de $4,5 \mathrm{~m}$ para coronar un monumento de 8 metros. Como vemos, no existe una relación proporcional estándar entre los cuerpos principales y los pyramidia que los rematan; por tanto es factible introducir variaciones en la altura de nuestro pyramidium manteniendo la metrología general propuesta.

Puede llamar la atención que, de los 34 sillares localizados, el número de piezas originales reinsertadas en el monumento sea sólo de nueve. Pero esta cifra es la que ha resultado tras la aplicación de meditados criterios que abogaban por la reubicación en el monumento de al menos un sillar original por hilada, siempre y cuando no existiera duda alguna respecto a la pertenencia de dichos sillares a esa hilada y a esa posición ${ }^{5}$.Se han descartado, en primer lugar, los que presentaran un estado de conservación excesivamente erosionado en sus caras vistas y, en segundo lugar, los que pertenecieran al alzado oeste del monumento, alzado que se ha dejado parcialmente abierto con el fin de poder seguir contemplando la estructura interna del mausoleo. También se ha descartado reubicar los sillares originales de la cubierta plana del monumento a línea de cornisa y previa al pyramidium (RuizAlcalde y Charquero, 2014, 167-169), ya que esto hubiera imposibilitado totalmente su contemplación, mientras que su disposición actual al pie de la torre permite explicar, a partir de éstos, las particularidades constructivas que tienen las cubiertas romanas de estas características.

5. La no inclusión del sillar $n^{\circ} 5$, que en el anterior artículo se incluía entre la línea de capiteles y que existía la posibilidad de que albergara el titulus sepulcralis viene derivada del criterio seguido de no reubicar los sillares cuyo emplazamiento no se pudiera asegurar con total certeza (Ruiz-Alcalde y Charquero, 2014, 165-167). En la actualidad, existe otra hipótesis al respecto del titulus sepulcralis contemplada en el artículo de esta revista de A. Sellés y A. Espinosa.
La distribución de estas nueve piezas en el monumento ha venido marcada, en el caso de los sillares cuyas caras internas se adaptaban a la bóveda, por la única posición que esto permitía (TSJ 33, y TSJ 18). Sin embargo, en la mayoría de los casos, dentro de su pertenencia a una hilada determinada, los sillares admitían una colocación aleatoria en cualquiera de los lienzos. Se ha cuidado entonces la presencia de sillares originales en cada uno de los lienzos, distribuidos en base a un criterio estético e incluyendo un número de sillares ligeramente mayor en el alzado norte de la torre, por ser éste el que recibe al visitante (Figs. 23 y 24).

\section{EL RECINTO FUNERARIO}

En el pasado artículo ya presentamos una estructura muraria de opus caementicium que rodeaba el monumento por el norte y el oeste y que constituía el recinto funerario del monumento (Ruiz-Alcalde y Charquero, 2014, 177-179). Las intervenciones de 2014/2015 han sacado a la luz nuevos tramos de esta misma estructura que han permitido conocer el trazado y dimensiones totales del recinto, identificar una posible puerta de acceso y profundizar en su técnica constructiva.

Sobre unos cimientos de mampostería irregular trabada con argamasa que tienen una anchura de 58/62 $\mathrm{cm}$ se erigiría un alzado de $50 \mathrm{~cm}$ de ancho realizado mediante encofrado romano. Restos de este encofrado sólo se han conservado en el área noreste de la excavación y en un punto al oeste del monumento. Al ser cimentaciones los restos localizados en esta campaña, y aparecer cortando niveles geológicos sin ningún tipo de zanja de cimentación, no se han exhumado materiales del momento constructivo. Sin embargo, la campaña del 2012 sí que nos permitió fechar la estructura a mediados del siglo II d.C. coincidiendo con el momento en que se erige la torre (Ruiz-Alcalde y Charquero, 2014, 176-177).

La localización en esta campaña de dos de los flancos del recinto funerario, concretamente el sur y el oeste -este último reutilizado como muro de cierre de un espacio habitacional de época moderna-, sumados a los tramos ya conocidos, permite ubicar hipotéticamente la cuarta esquina -seguramente destruida con la construcción de una balsa en la segunda mitad del siglo XX-y, así, cerrar el perímetro del recinto.

La planta que presenta este recinto es trapezoidal, de $18,60 \mathrm{~m}=63$ pies romanos de norte a sur y 16,29 $\mathrm{m}=55$ pies romanos de este a oeste, es decir, que tendría una superficie de $303 \mathrm{~m}^{2}=3465$ pies cuadrados (Fig. 25).

El lado más largo del recinto coincide con el lado en el que se ha identificado el posible vano de acceso situado al oeste del monumento, por lo que podríamos identificar este lado mayor como el de la fachada principal o in fronte, que conectaría con el camino de acceso a la vía, y el lado más corto como la profundidad del recinto o medida in agro. 


\section{Hilada $10^{\mathrm{a}}$ Arquitrabe}

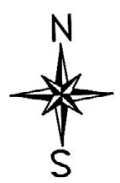

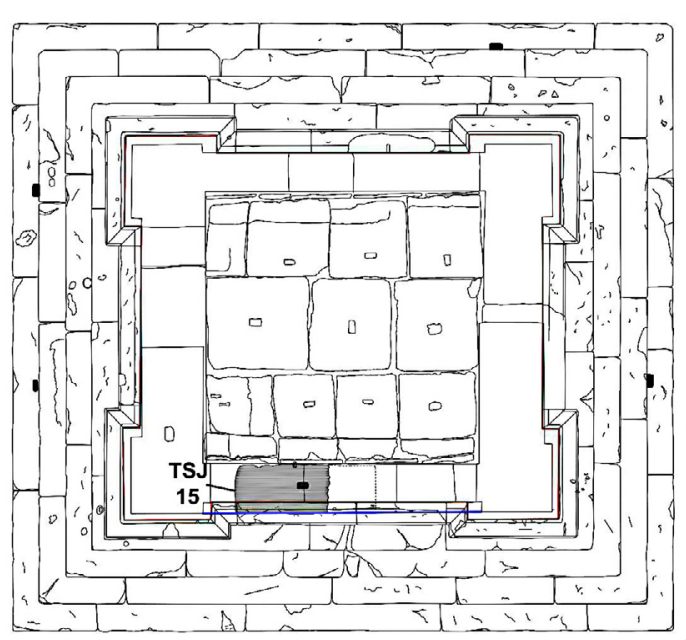

Hilada $10^{\mathrm{a}}$ (línea de arquitrabe $)=62 \mathrm{~cm}$

Alzado Sur

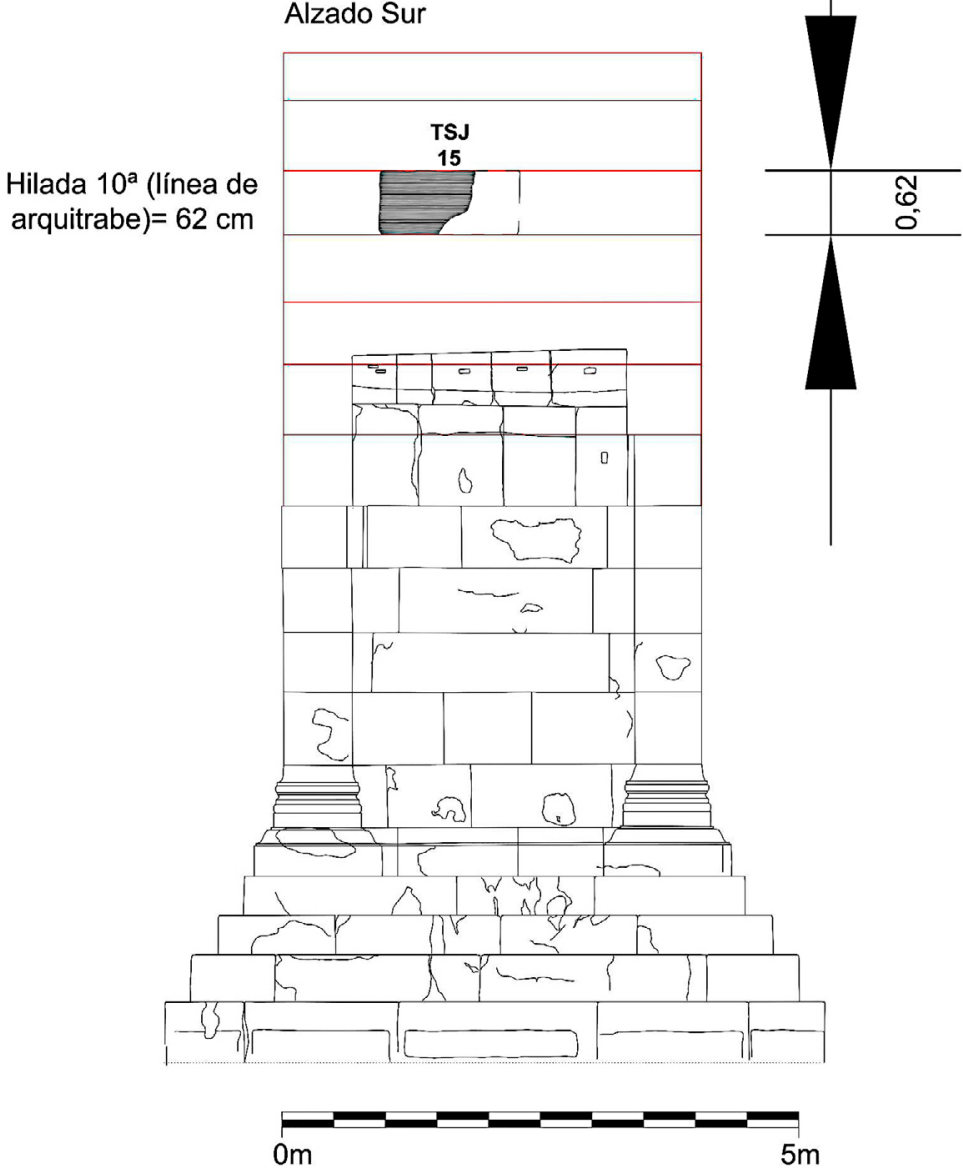

Figura 18: Plano de reubicación de los sillares en la hilada décima o de arquitrabe del monumento.

Es una tendencia bastante generalizada que los recintos tengan unas medidas in fronte superiores $\mathrm{o}$, al menos, iguales a las in agro, para adquirir visibilidad y para facilitar el acceso al locus sepulturae (Vaquerizo, 2002a, 79); es lo que ocurre en nuestro caso, con 63 pies in fronte frente a 55 pies in agro; Hay dos indicios más de que ésta sería la fachada principal del recinto; uno, que el monumento no está ubicado en 


\section{Hilada $11^{\text {a }}$ Arquitrabe}
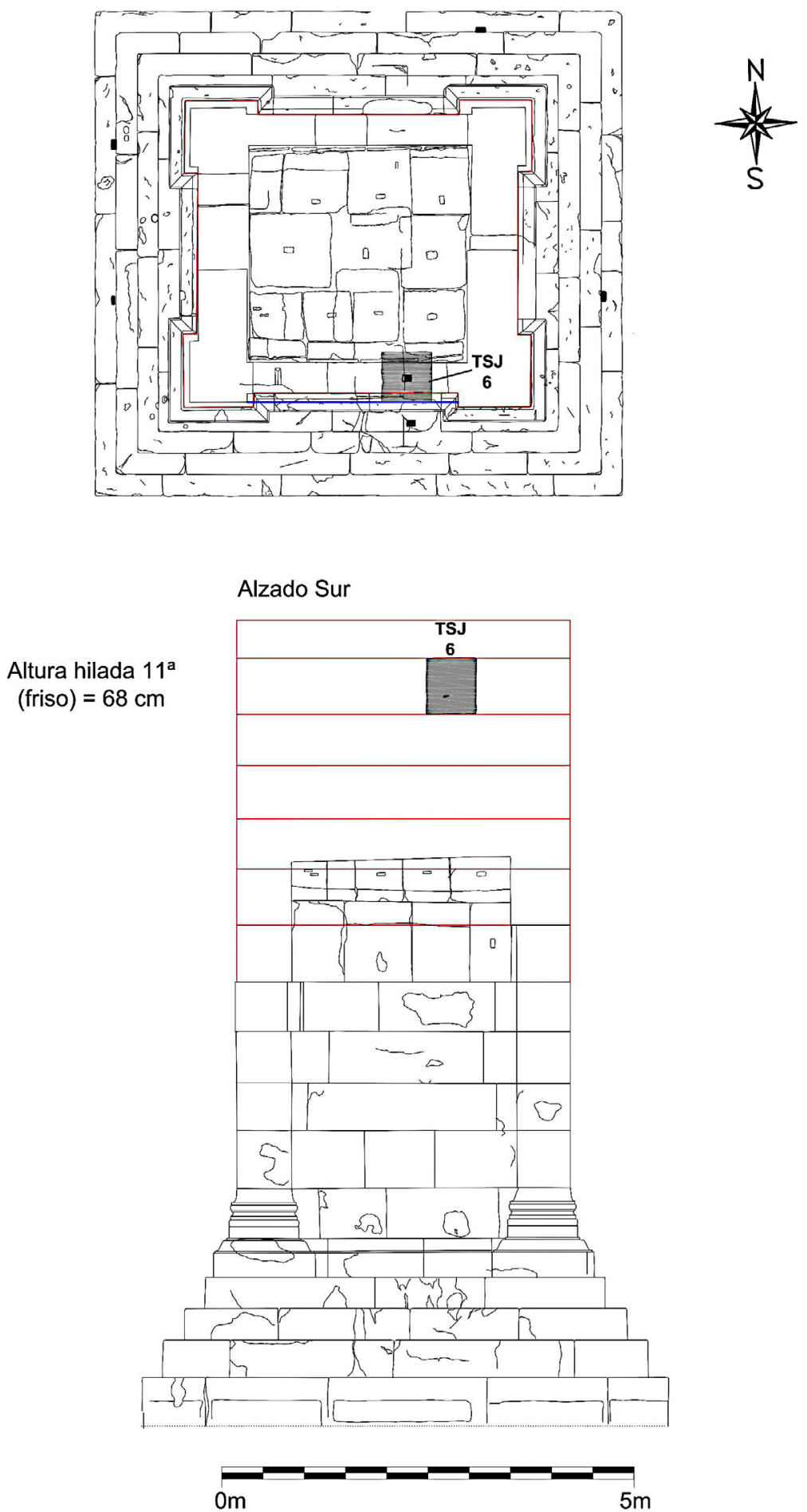

Figura 19: Plano de reubicación de los sillares en la hilada undécima del monumento.

una posición central respecto al acotado, sino que se encuentra más cerca de este muro que de cualquiera de los otros tres; y otro, que el vano de acceso al espacio sagrado se alinea con la abertura para libaciones que tiene la torre en su fachada oeste. Es decir, que cualquier visitante que entrara al recinto por este acceso se 


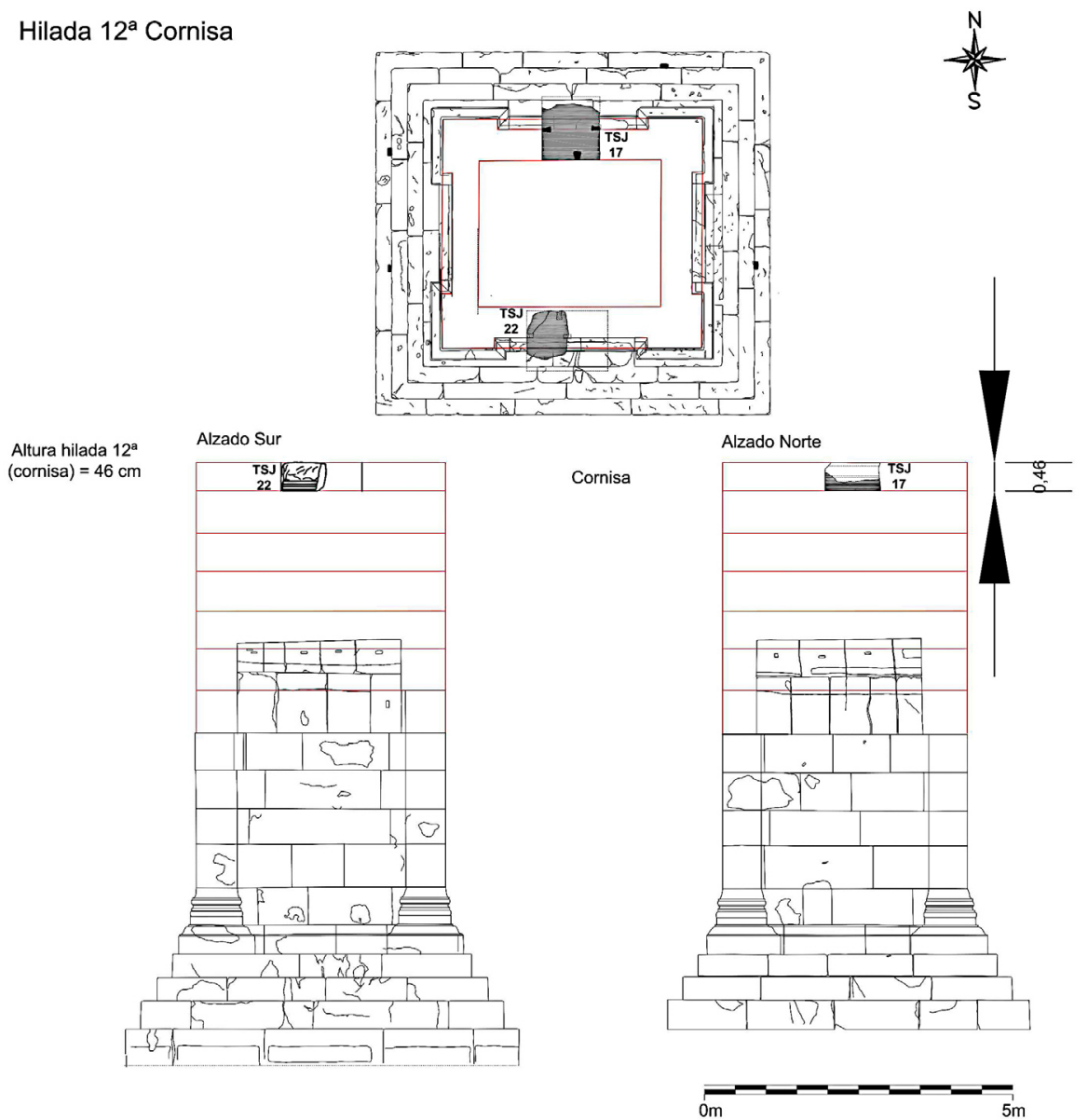

Figura 20: Plano de reubicación de los sillares en la hilada duodécima del monumento.
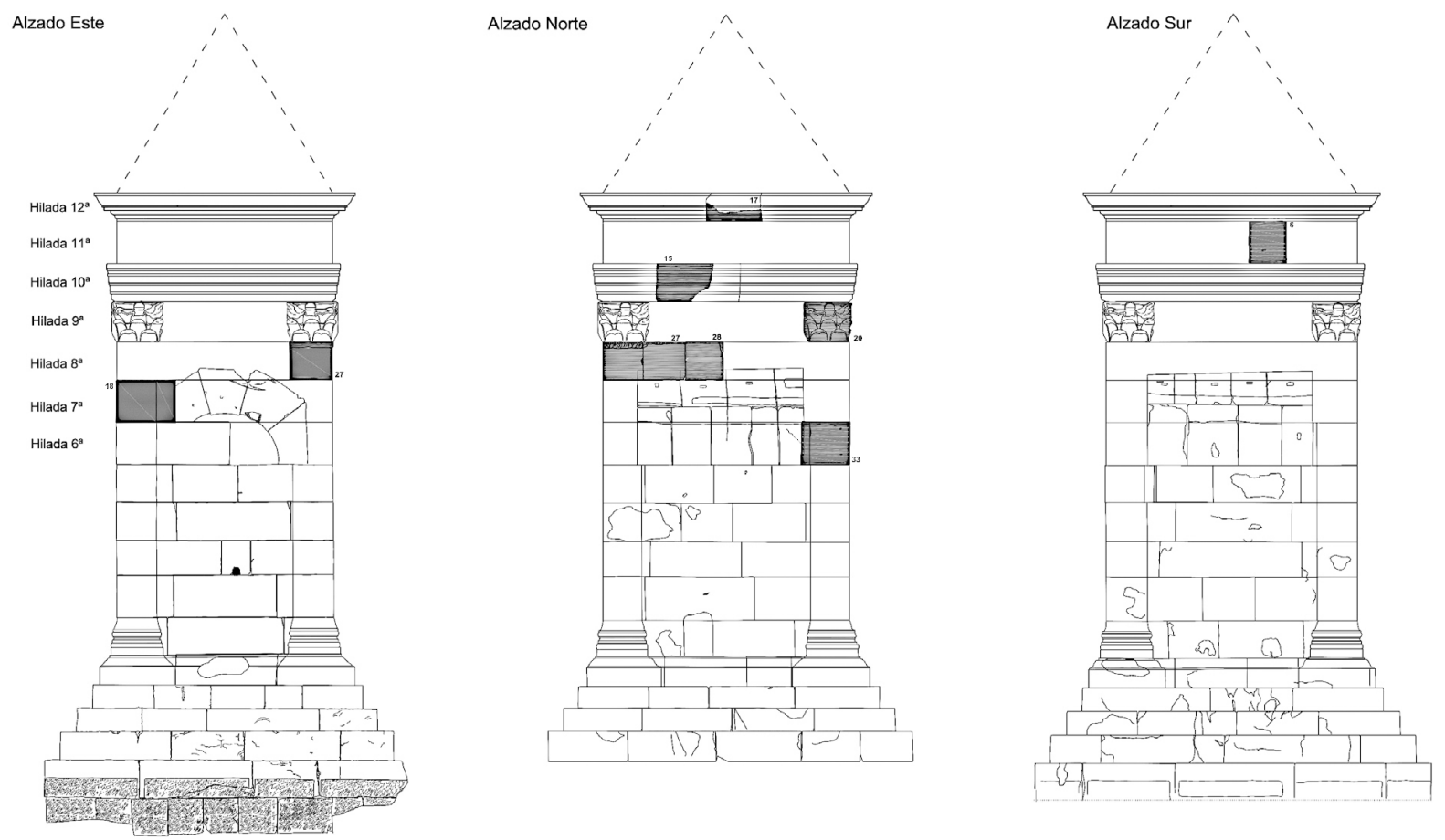

Figura 21: Plano de los alzados idealizados con los sillares originales ubicados. 


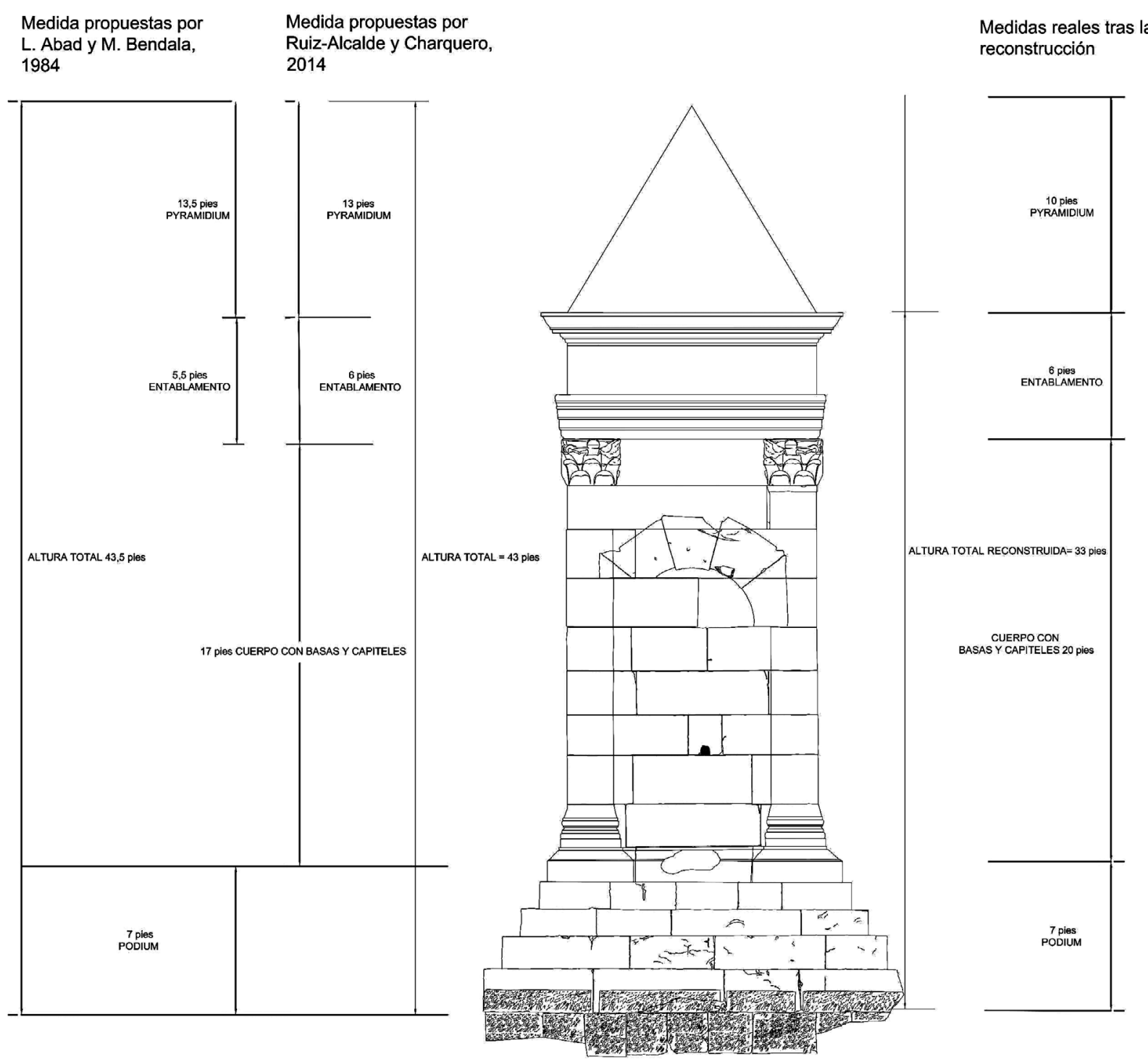

Figura 22: Resumen de las medidas propuestas en anteriores restituciones y en la presente.

encontraría de frente, y a pocos pasos, con el orificio por el que ofrecer su libación al difunto.

\subsection{LAS DIMENSIONES}

Dentro del conjunto de recintos funerarios hispanos, el acotado de la torre de Sant Josep con 63 x 55 pies excede las medidas estándar que éstos suelen tener y que se sitúan entre los 10/20 pies in fronte y 8/20 pies in agro. Es en la Hispania central y meridional donde se han documentado y estudiado un mayor número de estos recintos funerarios. Por ejemplo, en Augusta Emerita muchos de ellos reproducen el módulo de 12 x 8 pies y en Corduba, de 12 x 12 pies (Vaquerizo y Sánchez, 2008, 121).

Por otra parte, dentro del contexto del occidente del imperio romano, los recintos hispanos son de media superiores a los de Roma (10/14 pies in fronte), debido a la evidente escasez de suelo funerario en la
Urbs. Sin embargo, son similares a los de Aquileia (16 x 16 pies y 16 x 32 pies), y tienen unas dimensiones menores a los de Ostia (20/30 pies in fronte e in agro (500-600 p.c.) y a los de Sarsina (18/20 pies in fronte) (Rodríguez Neila, 1992, 72 ss.). A pesar de ello, nuestro acotado excede las dimensiones de estas últimas dos ciudades. Y como veremos más adelante, tendremos que irnos a las provincias de Galia y Britania para encontrar acotados de dimensiones similares.

Ahora bien, hay una serie de circunstancias que pueden explicar las generosas dimensiones de nuestro acotado; de entrada, el coste del terreno sepulcral en Hispania no debió ser tan alto como en Roma y otras grandes ciudades, como muestran las numerosas referencias epigráficas de concesiones de suelo público para el locus sepulturae que se han encontrado en la península Ibérica (Rodríguez Neila, 1991, 92).

Por otra parte, la categoría jurídica que tuviera una ciudad determinaba en buena medida el uso del suelo, no sólo común sino también funerario; es posible que 


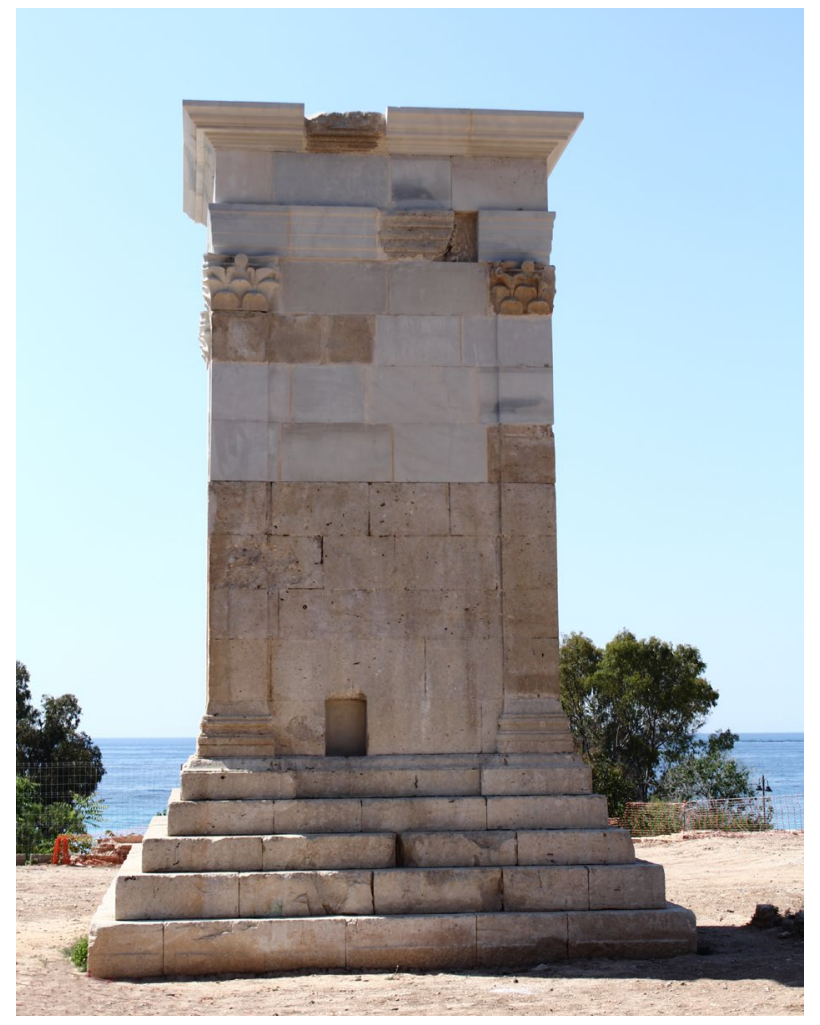

Figura 23: Vista de la Torre restaurada desde el norte. Mayo de 2015.

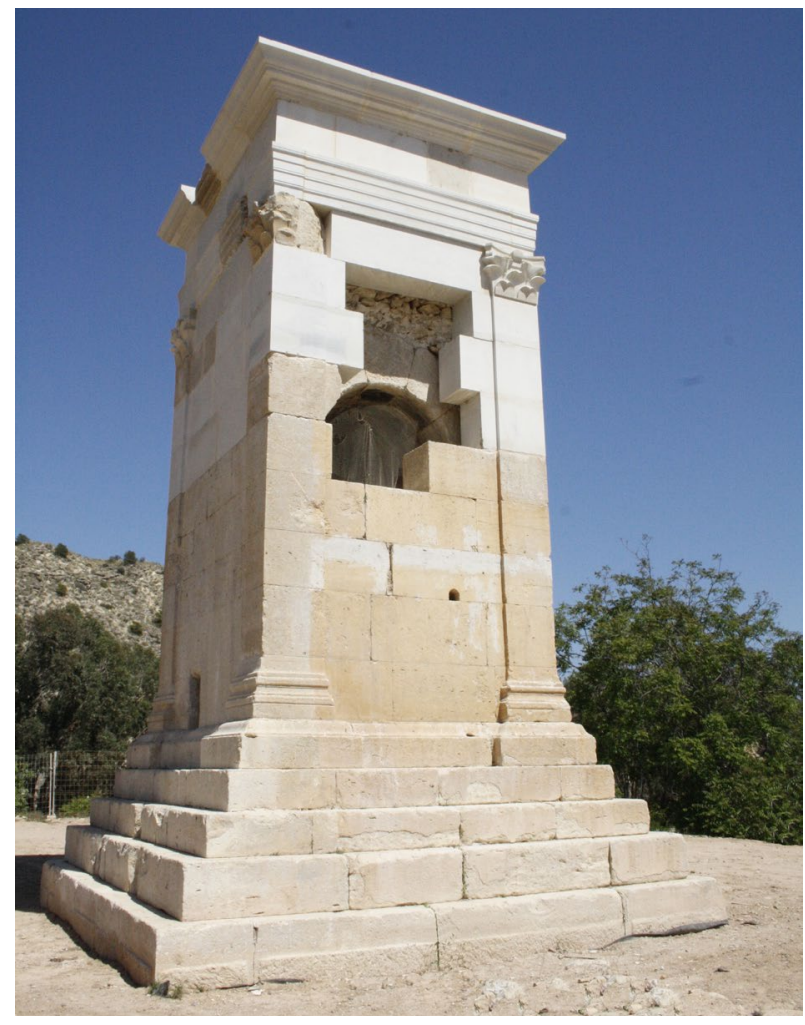

Figura 24: Vista de la Torre restaurada desde el este. Mayo de 2015.

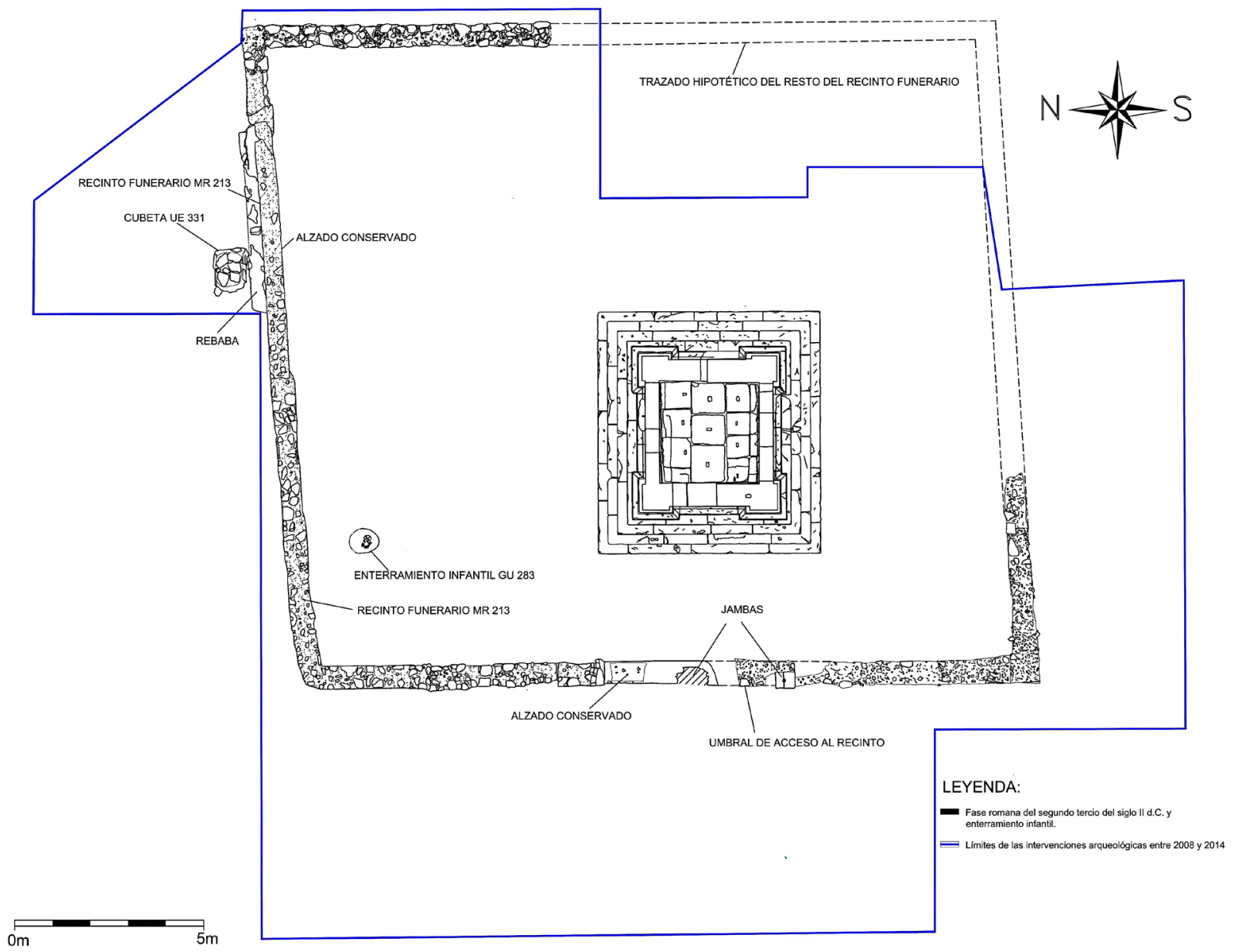

Figura 25: Planimetría del trazado del recinto funerario. 
en las colonias, el ordenamiento catastral abarcara incluso los espacios destinados a usos funerarios, y que como ocurre en las de Astigi, Augusta Emerita o Tuc$c i$, que presentan cierta regularidad en las medidas in fronte de sus recintos (10/15 pies), sus acotados fueran resultado de una serie de módulos acordados oficialmente o de una anterior parcelación (Rodríguez Neila, 1991, 81); por el contrario, en un municipium como el de Villajoyosa, la distribución del espacio sería más libre y carente de regularización en un origen, y por tanto, el planteamiento de los espacios de uso funerario pudiera haber sido más flexible.

A esto hay que añadir que este gran espacio que quedó acotado por el recinto de la torre de Sant Josep no se encuentra dentro de una necrópolis urbana sino en un enclave rural -vinculado a una villa- en lugar no aprovechable desde un punto de vista agrícola, y por tanto, menos costoso que en las áreas urbanas. Esta características son las que se han dado también en grandes áreas funerarias documentadas en la Bética (Vaquerizo, 2002 a, 116).

\subsection{AltURA Y ORNAMENTACIÓN}

No podemos conocer con exactitud la altura que el recinto de la Torre de Sant Josep tendría en su momento de construcción y uso, ya que su alzado máximo conservado no supera los $30 \mathrm{~cm}$. Hay que señalar que la altura de los recintos funerarios estuvo muy vinculada a la mentalidad de cada momento. En época augustea, eran bajos y sin decoración para permitir la ostentación pública del monumento y facilitar la atención del elemento de autorrepresentación que era la tumba (Von Hesberg, 1994, 73 ss.). La tendencia de estos recintos bajos fue hacia una mayor riqueza decorativa, que pretendía llamar la atención del viandante y, a la vez, destacar el área sepulcral del que formaba parte, como el Mausoleo de los Curii o la tumba de los Statii, ambos en Aquilea (Verzár-Bass, 2003, 225). Sin embargo, a lo largo del siglo II d.C. se va imponiendo un deseo de privacidad que ya no reclama la ostentación pública del monumento $\mathrm{y}$, consecuentemente, los recintos adquieren mayor altura para proteger del espectador la intimidad de la tumba, al tiempo que ganan monumentalidad en sí mismos (Vaquerizo, 2002a, 198-199). Los programas decorativos se centran entonces en el interior del acotado, mientras que el exterior de estos muros busca la mayor sencillez posible, para pasar inadvertido y así proteger un área de culto privada. En este sentido, algunas de las piezas encontradas en los alrededores del monumento, identificadas como coronamientos de pedestales de estatuas, nos hablan de la existencia de un programa arquitectónico de cierta entidad con carácter honorífico dentro del recinto. A ellas hicimos alusión en nuestro anterior artículo (Ruiz-Alcalde y Charquero, 2014, 173) y han sido objeto de estudio con mayor profundidad en otro artículo de esta misma revista (Véase Sellés y Espinosa).
Pensamos que nuestro monumento encajaría mejor, aunque con ciertas salvedades, en la línea de los recintos de mayor altura y que buscan centrar la atención en su interior, comunes en el siglo II d.C., momento en que se erige la torre. Por un lado, pensamos que su técnica constructiva, mediante muros de encofrado sobre una importante cimentación, es propia de un recinto bastante elevado y por otro lado, su alzado exterior liso en los puntos donde se ha documentado implicaría una cierta austeridad decorativa.

A pesar de la sencillez exterior del recinto, una huella de sillar localizada en esta campaña (Fig. 26) en la esquina suroeste del muro indica que al menos este ángulo estaría realizado mediante sillería. Las otras dos esquinas conservadas, situadas en el flanco norte del acotado, no presentan ningún tipo de huella que implique la existencia de sillares. Pero la cuarta esquina no ha llegado hasta el presente, ya que seguramente fue destruida durante la construcción de una balsa a principios del siglo XX, que sería también de sillería, por dos motivos; el primero es que la cota del nivel geológico, en el que está embutida la cimentación del recinto, desciende en este flanco del tossal bruscamente, y unos sillares esquineros le proporcionarían un refuerzo añadido; el segundo es que este ángulo, junto con la esquina en la que hemos hallado la huella de sillar, es el que enmarca la fachada del recinto visible desde el mar, dotando de una más acentuada monumentalización a la visión frontal que los transeúntes marítimos tendrían del recinto.

Refuerzos mediante sillería los encontramos también en recintos funerarios de Britania muy similares al nuestro, aunque sus muros están realizados en mampostería: el recinto funerario de Southfleet, en Kent, presenta cuatro contrafuertes en las esquinas y dos más en cada uno de los lados, y en el de Shorden Brae, en la actual Northumberland, se han localizado en las esquinas numerosos sillares que sugieren lo mismo, aunque sin el retranqueo del contrafuerte. Además, en este caso, junto a los sillares se han localizado esculturas de leones que coronarían las esquinas (Gillam y Daniels, 1961).

Esta parece haber sido un tipo de decoración muy recurrente en esta provincia del imperio; sin embargo, hay otro tipo de esculturas, como pináculos o bustos, que presentan claros indicios de haber sido colocadas en las esquinas de los recintos funerarios (Brewer, 1986, 26-7).

Nuestro recinto, pensamos, podría estar coronado en las esquinas meridionales por elementos decorativo-escultóricos que estarían en relación con los sillares esquineros de este flanco.

A pesar de que no hemos encontrado restos de la decoración escultórica, si tenemos en cuenta que el elemento más recurrente para decorar esquinas de recintos funerarios es el pináculo, como ocurre en el recinto D de Albingaunum (Albenga), podemos suponer que ésta fue también la decoración en nuestro caso. Tal y como señalan Massabò y Mennella (2003, 146) 


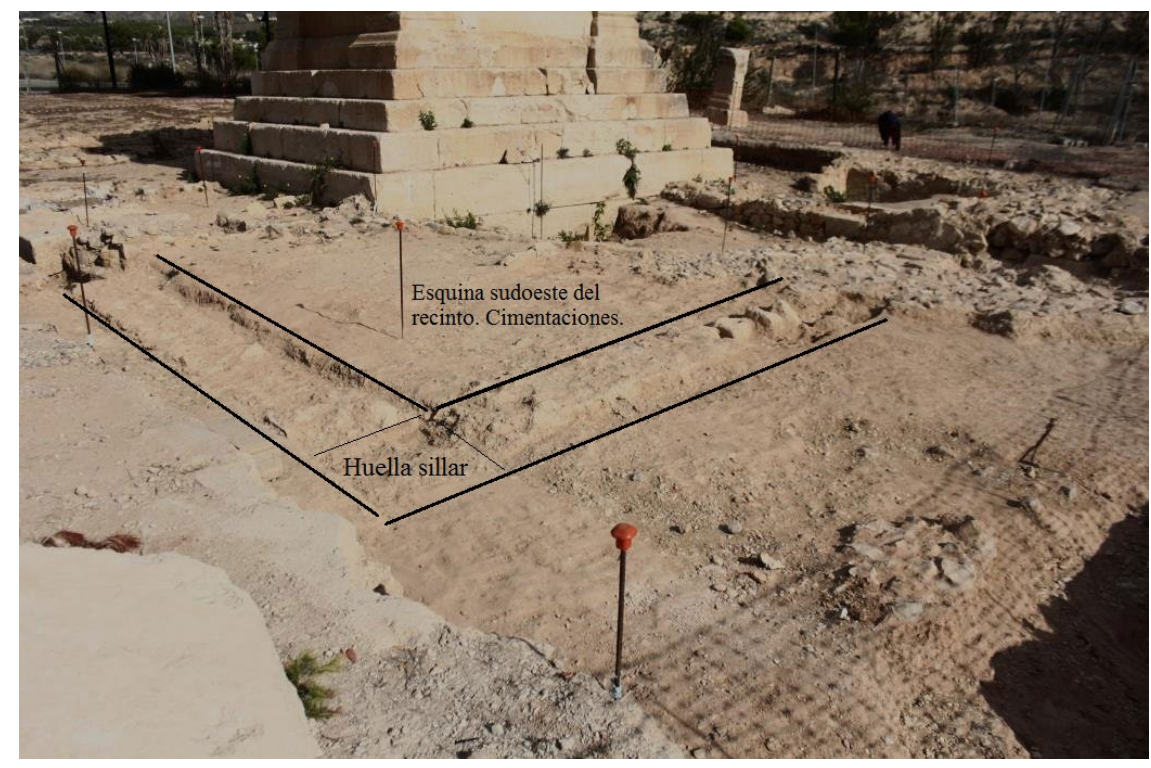

Figura 26: Cimentaciones de la esquina suroeste del recinto funerario, donde se aprecia la huella del sillar.

respecto a la coronación mediante pináculos, se trata de «una tipología [---] que intentaba mediante estos elementos evocar las murallas con torres de la ciudad de los vivos y que suponen una clara alusión a la inviolabilidad del espacio destinado a los difuntos»». En nuestro caso, este mensaje estaría destinado a los navegantes que contemplaran el recinto desde el mar aunque esto no deja de ser una mera hipótesis.

Por último, en relación a este tema debemos señalar que debido a la altura que presenta nuestro monumento funerario, más de $12 \mathrm{~m}$, la altura del recinto, aunque fuera importante, no enmascararía en ningún modo la monumentalidad del sepulcro.

\subsection{EL ACCESO}

Una de las aportaciones más sustanciosas de esta campaña en cuanto a datos sobre el recinto funerario, a la que ya hemos hecho referencia, ha sido el descubrimiento en el muro oeste del recinto, de lo que creemos pudo ser el umbral que daba acceso al interior del espacio funerario.

De este acceso se conserva una de las jambas, consistente en un sillar con un orificio central que fue reutilizado posteriormente como agujero de poste para soportar la techumbre de un patio de finales del siglo XIX. De la otra jamba de esta puerta romana queda únicamente la huella de sus cimientos, al norte de la anterior. Esta fosa, abierta para asentar en su momento el sillar de la jamba romana, se utilizó desde finales del siglo XVII hasta finales del siglo XVIII, como superficie de decantación entre dos balsas y posteriormente fue expoliada.

Destacable es que el sillar de jamba conservado in situ tiene una cota superior que coincide no sólo con el arranque del alzado del recinto funerario conservado en otras zonas, sino también con la línea superior del almohadillado que tiene la grada inferior del monumento; es decir, que la cota de la base de la jamba, y por tanto, del umbral identificado, es exactamente la cota de circulación usada en época romana, hoy perdida por la erosión y las diferentes fases constructivas posteriores (Ruiz Alcalde y Charquero, 2014, 178-179).

Finalmente hay que destacar dos datos significativos; por un lado, la luz que presenta este umbral es de 2,4 m es decir, exactamente 8 pies romanos, y por otro, que como ya hemos explicado, este umbral está alineado con el orificio de libaciones que tiene la torre en su alzado oeste, que no está centrado respecto a las pilastras del monumento, sino ligeramente desplazado hacia la pilastra meridional.

Existen ejemplos de recintos sin ningún tipo de acceso, tanto en Italia como en Hispania (Von Hesberg, 2005, 66; Vaquerizo y Sánchez, 2008, 121), a los que se supone que se accedía, o bien saltándolos si su altura lo permitía, o bien mediante escaleras portátiles o incluso de obra si estos eran algo más altos, como la documentada en el Recinto $\mathrm{G}$ de la necrópolis occidental de Albintimilium (Massabò y Mennella, 2003, 148).

Sin embargo, la tendencia a la monumentalización que siguen los recintos a partir del siglo II d.C. conlleva, asimismo, que muchos de los acotados se doten, como es nuestro caso, de acceso. Salvando las distancias, porque son recintos que encierran monumentos hipogeicos, encontramos ejemplos de puertas de acceso, más o menos monumentalizadas, en la Avda. de las Ollerías o en el Camino viejo de Almodóvar, ambos en la Colonia Patricia Corduba (Ruiz Osuna, 2005).

En lo que respecta a accesos a recintos funerarios ubicados en ámbitos no urbanos y que delimiten monumentos centrales, los casos en que se puede asegurar su existencia son escasos; los más destacados son el recinto británico de Shorden Brae en Northumberland, 
cuya restitución hipotética presenta una entrada de jambas de sillares ligeramente sobresalientes (Gillam y Daniels, 1961), y el recinto funerario romano de Harpender (Hertfordshire), con una entrada en el centro de uno de sus lados (Toynbee, 1996, 92). En nuestro caso, el acceso se realizaría por el muro oeste del recinto mediante una puerta cuyas jambas estarían realizadas mediante sillares, ligeramente adelantados respecto a la línea exterior del muro, lo que dotaría a la entrada de una cierta relevancia.

A la puerta de nuestro recinto pensamos que llegaría un camino secundario, seguramente un camino vicinalis de una de las vías que, por el este, conectaba la ciudad romana de Villajoyosa con lo que son hoy las ensenadas de Benidorm y Altea.

\subsection{El CARÁcter individual de ESTE CONJUNto FUNERARIO}

Dentro de este recinto se ha localizado como único enterramiento junto al sepulcro principal una inhumación infantil, de difícil datación, pero muy probable adscripción romana, dado el carácter sacro del lugar en que fue enterrado. Parece que esta desproporción entre un área acotada tan extensa y sólo dos enterramientos (uno de ellos el original de la torre), no es un caso insólito dentro del panorama funerario hispano imperial. Tal y como señala Rodríguez Neila, no hay ninguna relación proporcional entre superficie de acotados y número de personas enterradas en ellas, es más, suele haber espacios de 100, 200 o 300 pies con un único enterramiento, o como mucho hasta tres; pero también recintos que acogen múltiples deposiciones, y cuyas dimensiones no superan las de los loca individuales (Rodríguez Neila, 1991, 82). Este hecho se detecta también en Roma, donde predominan las fachadas de 12 pies in fronte y múltiples enterramientos, o en Emilia Romagna, donde se observa que mientras recintos de cierta amplitud acogen muy pocos enterramientos, éstos se multiplican a veces en otros recintos más reducidos (Vaquerizo y Sánchez, 2008, 118).

No hay por tanto, relación entre las dimensiones del locus, y el número de personas enterradas en él, como tampoco parece haberla entre las dimensiones del recinto y el nivel económico, la profesión o el sector social al que hubiera pertenecido el difunto (Cenerini, 2003, 139). No obstante, hay autores que señalan que acotados muy grandes con muy pocos enterramientos en su interior podrían ser áreas destinadas a acoger aún más enterramientos en el futuro (Rodríguez Neila, 1991, 81).

Por tanto no podemos más que formular hipótesis acerca de cuál fue el caso en la torre de Sant Josep, pero el haber hallado únicamente una inhumación infantil (puntual) dentro del terreno sagrado del recinto, nos lleva a pensar que muy posiblemente el acotado se construyó con la finalidad de acoger el mausoleo turriforme con carácter de espacio funerario individual.

\subsection{CONJUNTOS FUNERARIOS DE CARACTERÍ́STICAS SI- MILARES EN EL OCCIDENTE DEL IMPERIO}

Los conjuntos funerarios más similares al nuestro, en cuanto a medidas, están en las provincias de Britania y Galia; el primero de ellos lo encontramos en Harpender (Hertfordshire), con un recinto de 100 pies de mampostería trabada con barro. En Southfleet (Kent), fue localizado un recinto de 50 pies de largo, con contrafuertes tanto en las esquinas como en sus lados. También en Kent hay un acotado de 80 pies.

Mayores similitudes con el nuestro tanto en tipología como en cronología presenta el área funeraria de Shorden Brae, en Northumberland, sepulcro de un personaje destacado relacionado con el núcleo urbano de Corstopitum, pero en las afueras de éste. Se trata de un recinto de 135 pies de longitud, que originalmente encerró un monumento turriforme que cubría un enterramiento en fosa y fechado en el segundo cuarto del siglo II d.C. (Gillam y Daniels, 1961). Las esquinas de este recinto estaban realizadas con sillares, como hemos reseñado anteriormente, $\mathrm{y}$ adornadas con leones.

En cuanto a paralelos hispanos, el caso más claro lo encontramos en el recinto que rodea el sepulcro turriforme del Castellet de les Corts, en Ampurias. Lo que se ha conservado del monumento es un núcleo de opus concretum de $5 \mathrm{~m}$. de largo y 3,5 de ancho, que iría revestido con sillares, hoy desaparecidos (Almagro, 1951, 2). Este monumento está rodeado por un muro también de opus concretum y con un revestimiento de sillarejo, tiene un grosor de $0,40 \mathrm{~m}$ y una altura de 1,4 $\mathrm{m}$. Al igual que en nuestro caso, la torre de «El Castellet» no está centrada respecto al recinto, que también presenta una planta trapezoidal, cuyas esquinas están también reforzadas con pilares. Aunque parece que el monumento central no alberga enterramiento, en el sector norte del recinto se concentran 28 enterramientos de inhumación. Las ánforas asociadas a éstos dan una cronología del siglo III d.C., es decir, algo posterior a la nuestra; sin embargo, es posible que los enterramientos se fueran produciendo en momentos posteriores a la construcción del monumento principal, como pensamos que ocurre con el enterramiento infantil localizado en la Torre de Sant Josep.

\subsection{ConteXtualización DENTRO DE LA ARQUiteCTU- RA FUNERARIA ROMANA}

Los recintos de obra con carácter individual tienen su origen en el siglo II a.C. en Roma. Surgieron para dar respuesta al incipiente deseo de la población más privilegiada de desligarse de las necrópolis comunes situadas generalmente en las vías de entrada a las ciudades. Buscaban descansar en un enclave individualizado que les proporcionara una autorrepresentación más personalizada (Von Hesberg, 2005, 64). Uno de los primeros recintos que conformaba en sí mismo un cementerio es el monumento de los Concordii, en 


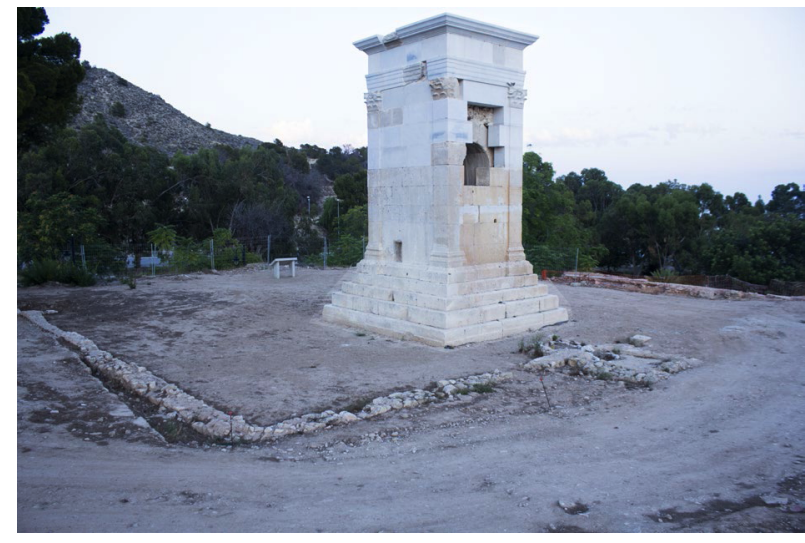

Figura 27: Vista desde el noroeste de la Torre reconstruida y de su recinto funerario. Junio de 2015.

Reggio Emilia (Italia). Esta costumbre se fue extendiendo por las provincias occidentales más romanizadas, como atestiguan los numerosos ejemplos que hay en la Galia Narbonensis y en la Hispania Ulterior Baetica (Vaquerizo, 2002b, 171).

Nuestro caso de estudio encaja en estas características, ya que el difunto de la torre de Sant Josep decidió ubicar su tumba, en un enclave alejado de las necrópolis urbanas asociadas a los caminos que desde el norte y el oeste conducían al municipium ${ }^{6}$, (Espinosa, Ruiz-Alcalde y Marcos, 2011), seguramente movido por un deseo de auto-ensalzamiento, y también de construirse un mausoleo próximo a su villa.

Los recintos de obra como el nuestro no eran los únicos que poblaban la escena funeraria romana; éstos convivían también desde el siglo II a.C. con acotados realizados mediante cipos de piedra que contenían referencias explícitas al límite perimetral (indicatio pedaturae). No obstante, esta modalidad epigráfica respondía más a la mera delimitación del espacio sagrado que a la monumentalización del mismo. Por tanto, pensamos que nuestro recinto de obra, dentro de unos terrenos más amplios asociados a la villa del difunto, y que previamente ya eran de su propiedad, pretendía enfatizar la monumentalización del conjunto más que responder a una necesidad práctica de delimitación parcelaria (Fig. 27).

\section{CONCLUSIONES}

A la vista de las novedades que han aportado los trabajos en este último año, veíamos necesaria su presentación. La propuesta de reconstrucción presentada en

6. En las últimas dos décadas se ha localizado dos grandes necrópolis en Villajoyosa de cronología principalmente orientalizante e ibérica, pero con una fase romana atestiguada. Son las necrópolis de Les Casetes y Poble Nou (Ruiz-Alcalde y Marcos, 2011). Recientemente, a finales del 2014, se ha intervenido en un nuevo sector de Les Casetes que presenta una muy importante fase romana y tardorromana. el artículo anterior se ha llevado a la práctica, lo que nos ha permitido corroborar que, a falta de los datos de los últimos sillares hallados, la propuesta era correcta y realizable.

Todos los nuevos sillares del monumento hallados en la última intervención han tenido cabida en la propuesta y por tanto, en la reconstrucción real del mausoleo. La principal modificación ha sido la inclusión de una hilada más en el cuerpo del monumento, determinada por el hallazgo de sillares que presentaban una altura diferente a la de las piezas que habían sido localizadas anteriormente $\mathrm{y}$, sobre todo, por la forma de uno de los sillares que, además de formar parte del lienzo de la torre, estaba destinado a encajar en el extradós de la bóveda del monumento.

Consecuencia de estas adaptaciones ha sido el aumento de la altura del cuerpo del monumento en 85 $\mathrm{cm}$, lo que ha llevado a que ahora la torre alcance desde la base del pódium hasta la cornisa 9,71 metros, es decir 33 pies romanos. La metrología romana sitúa la altura total del monumento coronado por el pyramidium en 43 pies. Las piezas originales reubicadas recientemente en el monumento elevan la altura de éste hasta línea de cornisa hasta los 33 pies, lo que significa que el pyramidium faltante mediría 10 pies, es decir, 3 pies menos de los que se le asignó en la propuesta anterior. Ante la falta de restos materiales de este coronamiento piramidal, la reconstrucción del mausoleo se ha centrado en el cuerpo y entablamento del mismo.

La localización de nuevos tramos de un elemento esencial asociado a la torre, su recinto funerario, nos ha llevado a un conocimiento más amplio de todo el conjunto. Ahora sabemos que el monumento estaría rodeado por un recinto que acotaría un espacio sagrado de 303 metros cuadrados, es decir, una superficie que supera a la de la gran mayoría de recintos conocidos en Hispania y que vendría explicada por las características propias de un espacio funerario rural lejos del municicipium y dentro de un fundus privado como es el nuestro. Por otro lado, sabemos también que el acotado perseguía dos finalidades: proporcionar cierta privacidad a la par que completar la monumentalidad del conjunto funerario.

Tres décadas después de que se iniciaran los estudios e investigaciones sobre este monumento funerario, su reconstrucción se ha convertido en una realidad, y en un punto de partida para la puesta en valor del yacimiento.

\footnotetext{
Diego Ruiz-Alcalde Museo Municipal C/ Barranquet, 4 03570 Villajoyosa arqueoleg@villajoyosa.com

Ana María Charquero Ballester C/ Alonso Cano, 65, $3^{\circ}$-F 03014 Alicante anachb@hotmail.com
} 


\section{BIBLIOGRAFÍA}

ABAD CASAL, L. y BENDALA GALÁN, M., 1985: «Los sepulcros turriformes de Daimuz y Villajoyosa. Dos monumentos funerarios romanos olvidados», Lucentum, II, 147-184.

ALMAGRO BASCH, M., 1951: «El recinto sepulcral romano tardío de El Castellet de Ampurias», AEspA, 24, $n^{\circ} 83-84,99-116$.

ARANEGUI GASCÓ, C., 1995: «Los monumentos funerarios romanos descubiertos en Edeta (Llíria, Valencia)», Saguntum, 29, 197-210.

BREWER, R. J., 1986:Corpus Signorum Imperii Romani: Great Britain Volume I, Fascicule 5, Wales, Oxford.

CENERINI, F., 2003: «L'indicazione della pedatura nelle iscrizioni funerarie romane dell'Emilia Romagna (Regio VIII)», en G. Cresci Marrone y M. Tirelli (eds.), «Terminavit Sepulcrum». I recinti funerari nelle necropoli di Altino, Atti del Convegno (Venezia 3-4 dicembre 2003), 137-143, Roma.

ESCOLANO, G., 1610: Historia general de Valencia, Valencia.

ESPINOSA RUIZ, A., RUIZ-ALCALDE, D. y MARCOS GONZÁLEZ, A., 2011: «El municipi romà de Vila Joiosa $i$ el seu territorium», en La Vila Joiosa arqueologia $i$ museu, 154-173, Alicante.

GILLAM, J. P. y DANIELS, C. M., 1961: The Roman mausoleum on Shorden Brae, Beaufront, Corbridge, Northumberland, Northumberland.

HERAS MORA, F. y OLMEDO GRAGERA, A., 2010: «Dos nuevos monumentos funerarios en Augusta Emerita. Primer avance de los resultados de la intervención de la calle Almendralejo n ${ }^{\circ}$ 41, Mérida (Badajoz, España)», Bollettino di Archeologia online, 45-53.

LABORDE, A. de, 1806: Voyage pittoresque et historique de l'Espagne, París.

MARTÍNEZ VALLE, A., 1995: «El monumento funerario de la Calerilla», $A E s p A, 24, \mathrm{n}^{\circ} 68,259-282$.

MASSABÒ, B, y MENNELLA, G., 2003: «I recinti funerari romani della Liguria Occidentale», en G. Cresci Marrone y M. Tirelli (eds.), «Terminavit Sepulcrum». I recinti funerari nelle necropoli di Altino, Atti del Convegno (Venezia 3-4 dicembre 2003), 145-156, Roma.

PRADOS MARTÍNEZ, F., 2008: Arquitectura Púnica. Los monumentos funerarios, Anejos de AEspA 44, Madrid.

RODRÍGUEZ NEILA, J.F., 1991: «Espacios de uso funerario con indicación de medidas en las necrópolis romanas», Conimbriga, XXX, 59-94.
RODRÍGUEZ NEILA, J.F., 1992: «Algunas observaciones sobre los acotados funerarios romanos», en In Memoriam J. Cabrera Moreno, 437-448, Granada.

ROMANELLI, P., 1970: Topografia e archeologiadell'Africa romana, Torino.

RUIZ ALCALDE, D. y MARCOS GONZÁLEZ, A., 2011: «Épocas orientalizante e ibérica en Villajoyosa», en $L a$ Vila Joiosa arqueologia i museu, 100-117.

RUIZ-ALCALDE, D. y CHARQUERO BALLESTER, A. $M^{\mathrm{a}}$., 2014: «El monumento funerario de la Torre de Sant Josep de Villajoyosa: nuevos datos y propuesta de restitución», Lucentum, XXXIII, 151-182.

RUIZ OSUNA, A. B., 2005: «La via sepulchralis occidental: un ejemplo de monumentalización funeraria en Colonia Patricia», Anales de Arqueología Cordobesa, 16, 79-104.

RUIZ OSUNA, A., 2008: Topografia y monumentalización funeraria en Baetica: ConventusCordubensis y Astigitanus, Córdoba.

TOYNBEE, J. M., 1996: Death and burial in the Roman world, Baltimore.

VAQUERIZO, D., 2001a: «Formas arquitectónicas funerarias de carácter monumental en Colonia Patricia Corduba», AespA, 74, 131-160.

VAQUERIZO, D., 2001b (coord.): Funus cordubensium. Costumbres funerarias en la Córdoba romana, Córdoba.

VAQUERIZO, D., 2002a: «Recintos y acotados funerarios en Colonia Patricia Corduba», MM, 43, 168-206.

VAQUERIZO, D., 2002b (coord.): Espacios y usos funerarios en el Occidente Romano, en Actas del Congreso Internacional celebrado en la Facultad de Filosofia y Letras de la Universidad de Córdoba (5-9 junio, 2001), Córdoba.

VAQUERIZO, D y SÁNCHEZ, S., 2008: «Entre lo público y lo privado. Indicatio pedaturae en la epigrafía funeraria hispana», AEspA, 81, 101-131.

VERZÁR-BASS, M., 2003: «Nota sui recinto funeraridecorati in Cisalpina Orientale», en G. Cresci Marrone y M. Tirelli (eds.), «Terminavit Sepulcrum». I recinti funerari nelle necropoli di Altino, Atti del Convegno (Venezia 3-4 dicembre 2003), 225-237, Roma.

VON HESBERG, H., 1994: Monumenta: $i$ sepolcri romani e la loro architettura, Longanesi.

VON HESBERG, H. 2005: «Il recinto nelle necropoli di Roma in età repubblicana: origine e diffusione», en G. Cresci Marrone y M. Tirelli (eds.), «Terminavit Sepulcrum». I recinti funerari nelle necropoli di Altino, Atti del Convegno (Venezia 3-4 dicembre 2003), 59-69, Roma. 